\title{
DIRECT MONITORING OF TWINNING/DETWINNING IN A TWIP STEEL UNDER REVERSED CYCLIC LOADING
}

\author{
C. D'Hondt ${ }^{1,2}$, V. Doquet ${ }^{1 *}$, J.P. Couzinié ${ }^{2}$ \\ ${ }^{1}$ CNRS UMR 7649, Laboratoire de Mécanique des Solides, \\ Ecole Polytechnique - Institut Polytechnique de Paris, Palaiseau (France) \\ ${ }^{2}$ CNRS UMR 7182, Institut de Chimie et des Matériaux Paris Est, Thiais (France) \\ *Corresponding author: doquet@Ims.polytechnique.fr
}

\begin{abstract}
In situ tensile and reversed cyclic tests were run on a TWIP steel in a SEM, with High-Resolution Digital Image Correlation (HR-DIC) measurements of the plastic strain field in a few selected grains prone to twinning, with a spatial resolution between 150 and $250 \mathrm{~nm}$, or under an AFM, with measurements of surface steps height at emerging deformation twins. Evidences of detwinning upon load reversal, as well as quantitative data on twinning/detwinning/retwinning were obtained. Detwinning and retwinning, which often were only partial, in spite of a fully reversed loading, did not seem to start at the onset of stress reversal. It required a sufficient variation of the stress, close to the twinning stress (estimated as 400 to $475 \mathrm{MPa}$ ) in absolute value, so that a mechanical hysteresis of the local twinned fraction occurred. Primary and secondary twinning along the same plane, inducing axial plastic strains in opposite directions, also allowed some grains to accommodate reversed plastic strain. Under fixed stress amplitude ( $\pm 500 \mathrm{MPa})$, the twin fraction in all monitored grains saturated at values between 0.5 and $3.5 \%$, from the $2^{\text {nd }}$ cycle, while under fixed plastic strain amplitude $( \pm 0.5 \%)$, it increased in a ratchetting way during the whole cyclic hardening stage, reaching 0.5 to $5 \%$. In both cases, however, the plastic strain amplitude accommodated by twinning/detwinning, which reached $0.35-0.42 \%$ in some grains during the $1^{\text {st }}$ cycle, decreased down to less than $0.05 \%$ after 100 to 1000 cycles.
\end{abstract}

\section{Keywords}

Mechanical twinning, Detwinning, Cyclic plasticity, TWIP steel, Digital Image Correlation, AFM

\section{Introduction}

Twin boundaries generally hinder dislocation glide in metals and alloys. Their multiplication constitutes an efficient strengthening strategy, and their stability under mechanical loading has thus received attention. Mechanically-induced detwinning of growth twins in nanotwinned Face Centered Cubic (FCC) metals obtained by electro-deposition, magnetron sputtering or physical vapor deposition has been observed during in situ tensile tests in a TEM, and analyzed by molecular dynamics simulations [1, 2].

It is well established that mechanical twinning and detwinning operate in nanocrystalline FCC metals [3-5]. The dislocation-twin interactions potentially responsible for each of those two phenomena have been analyzed in detail [6]. Molecular dynamics simulations of tensioncompression loading on nanocrystalline alloys predicted a twinning/detwinning sequence [7]. Hu et al. [8] developed a phase field model, for mesoscale simulations of stress-induced twinningdetwinning in a FCC polycrystal.

By contrast, very few observations of stress-induced detwinning can be found in the literature for coarse grained FCC metals and alloys. Szczerba et al. [9] investigated detwinning in Cu-8.5Al single crystals. They defined three different detwinning modes, depending on the detwinning shear vectors: one denoted by "reverse mode" which restores both the initial shape and orientation of the crystal, and two "pseudo-reverse" modes, which restore only the orientation. The former occurred for a resolved shear stress equal to -0.42 times the shear stress needed for twinning, while the ratio of detwinning to twinning stress was -0.85 for the two "pseudo-reverse" modes. During a tensile test in a TEM on polycrystalline aluminum with a mean grain size of 65 
$\mu \mathrm{m}$, Li et al. [10] observed twinning at a crack tip during load increments, followed by complete detwinning during a displacement hold period leading to stress relaxation.

Mechanical twinning is known to play a central role in the tensile behavior of Twinning Induced Plasticity (TWIP) steels, but its role in their cyclic plasticity is far less understood. Contrary to Hexagonal Close-Packed (HCP) materials, like magnesium alloys, in which detwinning is so easy and profuse that it induces visible anomalies on the stress-strain loops upon load reversal, this is not the case in TWIP steels, for which no such "macro-scale signature" of detwinning has been reported (except for two papers, reported below, at deviance with the abundant literature on their cyclic plasticity). Evidences of detwinning in TWIP steels thus have to be searched at the micro-scale.

A few studies have recently investigated the possibility of detwinning upon load reversal in these materials, as summarized below.

Saleh et al. [11] applied 5 tension-compression cycles with $\pm 1 \%$ strain on a Fe-24Mn-3Al-2Si$1 \mathrm{Ni}-0.06 \mathrm{C}$ TWIP steel while performing neutron diffraction measurements. The positions of the diffraction peaks provided information on the mean elastic lattice strain over sets of grains sharing the same crystallographic orientation relative to the loading axis. They compared self-consistent crystal plasticity simulations of these tests -based either on perfect dislocation glide plus unidirectional twinning, or on forward and reversed partial dislocations glide only- and found a better agreement with the experimental data for the latter. They considered this as an indication in favour of detwinning.

Xie et al. $[12,13]$ also performed tension-compression tests on a TWIP steel (Fe-17.74Mn2.96Si-0.44Al-0.57C) with simultaneous neutron diffraction. Up to 1000 cycles were run at $\pm 0.8 \%$, which -surprisingly enough- did not lead to any cyclic hardening, but to slight anomalies in the shape of the first stress-strain loops, which the authors assumed to be related to detwinning. They observed a repeated increase and decrease in the intensity of some diffraction peaks within each loading cycle, especially for grain orientations known to favor twinning in tension or in compression. This was consistent with the repeated lattice reorientations associated with twinning/detwinning. However, since detwinning on a given system can change diffraction peaks in the same way as twinning on a different system, the interpretation of changes in diffraction peaks intensity is not straightforward. Furthermore, like in the work of Saleh et al. [11], the diffraction data were averaged other sets of grains sharing the same crystallographic orientation, but with potentially different sizes and surrounding grains orientations.

The most direct evidence of detwinning in coarse grained TWIP steel was obtained by McCormack et al. [14] who compared EBSD mappings of the same area of a Fe-24Mn-3Al-2Si-1Ni$0.06 \mathrm{C}$ steel sample pre-strained by $12.8 \%$ in tension $(\sigma \approx 600 \mathrm{MPa})$ and then loaded in compression, until the strain goes down to $3.1 \%(\sigma \approx-600 \mathrm{MPa})$. They observed the disappearance of some twin bundles formed in tension, and proposed a modification of a crystal-viscoplasticity self-consistent model to integrate detwinning.

The above-mentioned evidences of detwinning in TWIP steels were either indirect, or obtained after interrupted tests on unloaded samples, so that the local twinning/detwinning kinetics during cyclic loading remains unknown.

The Atomic Force Microscope (AFM), with its excellent spatial resolution, is very well suited to the study of mechanical twinning, and, combined with EBSD, it allows a precise identification of active twinning systems [15]. Many authors successfully used it for that purpose [15-17].

In the present work, observations of the twinning/detwinning process in Fe-22Mn-0.6C TWIP steel are made under cyclic loading, in a few isolated grains, chosen for their twinning propensity, using either high resolution digital image correlation (HR-DIC) during in situ tension-compression tests in a SEM, or high resolution topographic imaging during in situ tests under an AFM. The aim 
of these specific observations is not to reflect the overall behaviour of all grains, but to maximise the chances to observe twinning/detwinning/retwinning phenomena under fully reversed loading, and to document their threshold stress and kinetics, along cyclic tests, depending on the fixed parameter (stress or plastic strain range), which are largely unknown. This is important for a proper modelling of twinning/ detwinning in low stacking fault energy FCC alloys, using crystal plasticity or phase field approaches. It may also provide a better understanding of the role played by twinning in the cyclic hardening/ softening of TWIP steels. In an effort to obtain data more representative of the overall behaviour, some statistical data on twinning activity during cyclic loading, over an area containing nearly a hundred grains, will also be presented.

A comprehensive investigation of the macro-scale cyclic plasticity of Fe-22Mn-0.6C TWIP steel (plastic strain or stress-controlled tension-compression tests with measurements of the kinematic and isotropic components of the flow stress, constitutive modelling, and TEM observations) [18] was run in parallel with the present study, which rather focuses on the micro/nano-scale aspects. Some of the macro-scale results are used in this study (e.g. to choose the conditions of in situ tests), but most of it will be reported in a separate paper, in which the observed micro/nano-scale phenomena will finally be used to discuss the global cyclic behavior of the material.

The structure of this paper is as follows. The experimental techniques are first introduced, with an emphasis on the combination of HR-DIC and EBSD used to get quantitative and very local data on twinning, in grains prone to this deformation mode. Then, the SEM or AFM observations and measurements concerning the stress at the onset of twinning in tension, detwinning and retwinning threshold stresses and degree upon load reversal, and finally twinning-detwinning activity in tension-compression are detailed. Some grains are shown to exhibit both primary and secondary twinning along the same plane allowing them to accommodate reversed plastic strain, which has never been reported, to the best of our knowledge. After a substantial twinning activity during the monotonic plastic flow that occurs during the first loading ramp, a stagnation of the local twin fraction from the $2^{\text {nd }}$ cycle is observed under constant stress range, while a ratchetting rise is associated with cyclic hardening under fixed plastic strain range. Based on a statistical analysis over a hundred grains, differences in the way large and small grains accommodate reversed plastic flow are demonstrated. All those results are eventually discussed, with an emphasis on the role of neighboring grains and of the backstress they induce on twinning and detwinning as well as on secondary coplanar twinning, and the role of the forward prestrain on detwinning.

\section{Experimental procedures}

\subsection{Material, samples geometry and surface preparation}

The studied material is a TWIP steel produced by ArcelorMittal as a $36 \mathrm{~mm}$-thick hot-rolled plate whose chemical composition is given in table 1. The microstructure shows equiaxed grains and nearly no texture, whatever the observed section (Figure 1). Considering annealing twins as grain boundaries, the grain size ranged from approximately 5 to $110 \mu \mathrm{m}$, with an average of about $23 \mu \mathrm{m}$. The Stacking Fault Energy (SFE) of TWIP steels was mostly determined based on a thermodynamical approach. For a nearly similar composition, the different models yield a SFE between 19 and $31 \mathrm{~mJ} \cdot \mathrm{m}^{-2}$ [19-22].

Two types of samples were machined along the transverse direction. One has been used for in situ tensile tests in the SEM (Figure 2(a)) and the second for in situ tension-compression tests in the SEM or under an Atomic Force Microscope (AFM) (Figure 2(b)). The latter had a short gage length $(1.2 \mathrm{~mm})$ compared to its thickness $(0.6 \mathrm{~mm}$ in the central part) to reduce the risk of buckling in compression. 
Table 1

Chemical composition of the TWIP steel (weight \%)

\begin{tabular}{llllllll}
\hline $\mathrm{Mn}$ & $\mathrm{C}$ & $\mathrm{V}$ & $\mathrm{Si}$ & $\mathrm{Cr}$ & $\mathrm{P}$ & $\mathrm{N}$ & $\mathrm{Fe}$ \\
\hline 22.29 & 0.63 & 0.20 & 0.23 & 0.19 & 0.03 & 0.01 & bal. \\
\hline
\end{tabular}

(a)
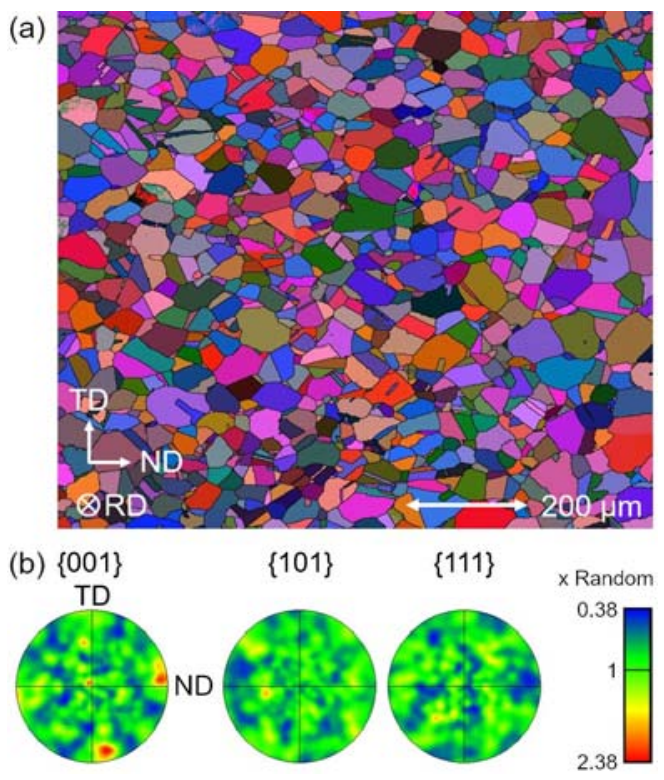

Figure 1: (a) Euler angles map and (b) pole figures along RD of the TWIP steel

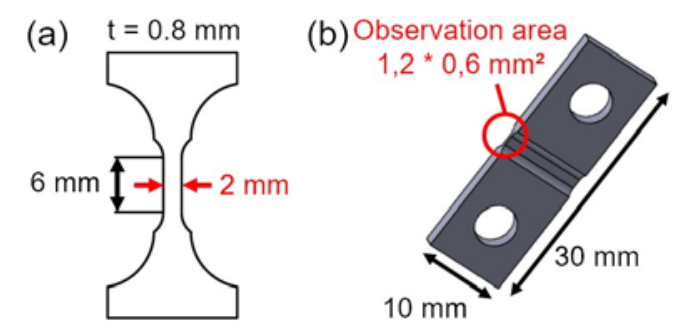

Figure 2: Dimensions (a) of the in situ tensile tests specimen (with a thickness t of $0.8 \mathrm{~mm}$ ) and (b) of the in situ tension-compression tests specimen

The surfaces to be monitored during the tests were first mechanically polished down to $1 \mu \mathrm{m}$. The samples were electropolished in a cooled $90 \%$ acetic acid $+10 \%$ perchloric acid solution during 5 min at $12 \mathrm{~V}$-or further mechanically polished with colloidal silica suspensions (Struers OPU and OPS) before a final ionic polishing stage to remove most of remaining silica particles.

Electron beam lithography was used to print a square-shaped gold grid with a pitch of $4 \mu \mathrm{m}$ over a $800 * 800 \mu \mathrm{m}^{2}$ area on the samples used for the tensile tests. This grid was used for digital image correlation measurements of the mean axial plastic strain, by averaging the axial plastic strain over the $800 * 800 \mu \mathrm{m}^{2}$ area, using the $\mathrm{CmV}$ software [23].

EBSD mappings were performed to determine grains orientations with a FEI XL40 FEG-ESEM Scanning Electron Microscope using the Aztec software from Oxford Instruments. It allowed the selection of a few grains to monitor, expected to twin in tension and/or in compression, based on the values and signs of the twinning Schmid factors, as well as on their relatively large size (79 to $112 \mu \mathrm{m}$ ), compared to the average, which should also favor twinning according to many authors $[4,24-27]$. These grains were generally not neighbors, but rather scattered over the whole gage length. The corresponding Schmid factors on all twinning and slip systems are gathered in table 3 (Appendix A), for each of the grains mentioned in the Experimental observations section. 


\subsection{In situ testing machines}

Two custom-made testing devices were used: a displacement-controlled $5 \mathrm{kN}$ tensile machine, for monotonic loading in the above-mentioned SEM, and a $\pm 4 \mathrm{kN}$ tension-compression machine (Figure 3), fitted either on the stage of the same SEM or on the side of the motorized stage of a Brüker Dimension Icon AFM, below the scanning head. For the latter machine, the load is applied in a symmetrical way, so that the area of interest remains centered. The machine is grounded to avoid electromagnetic perturbation of the piezo-actuators in the scanning head during image recording. Although the machine is basically displacement-controlled, a software allows tensioncompression cycling between specified peak/valley loads, as well as the application of series of segments connecting tabulated loads. The latter mode was used to mimic a plastic straincontrolled test, which had been done previously on a classical testing machine, using a cylindrical specimen fitted with an extensometer, and during which the evolution of the minimum and maximum stresses had been registered throughout the cyclic hardening and softening stages. The specimens were not mounted with the widest side of their gage length horizontal, but rather vertical, so as to increase the bending stiffness around the horizontal axis normal to the loading direction. This prevents undesirable upward (respectively downward) bending of the sample when it is loaded in compression (respectively tension). The monitored area is thus only $1.2 * 0.6$ $\mathrm{mm}$ large, which allows a preliminary mapping of grains orientations over the whole surface before testing. For AFM imaging, the Peak Force Tapping mode was adopted, and a sharp silicon nitride tip with a $2 \mathrm{~nm}$ tip radius and $15^{\circ}$ and $25^{\circ}$ front/back angles was used.

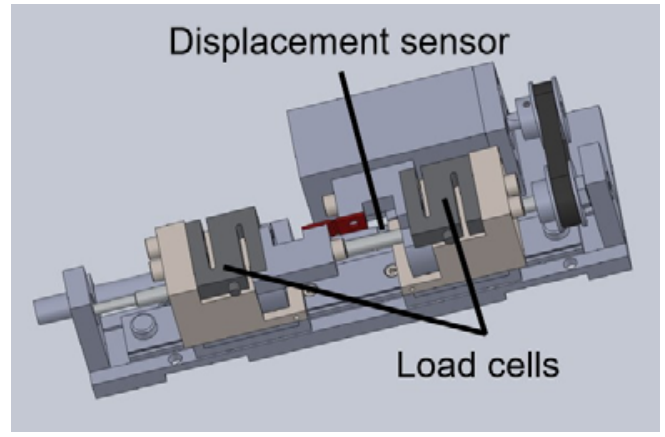

Figure 3: Tension-compression testing machine for in situ tests under an AFM or in a SEM

\subsection{Quantitative monitoring of twinning based on HR-DIC}

The early detection of twinning in TWIP steels is challenging using EBSD because of the insufficient spatial resolution of this technique with respect to the small initial thickness of the twins $(10-20 \mathrm{~nm})$. However, thanks to the very large shear strain $(\gamma=1 / \sqrt{2}=0.707)$ inside them, nanotwins can be detected using HR-DIC measurement of the plastic strain field.

Efstathiou and Sehitoglu [28] used DIC to monitor twinning in Hadfield steel single crystals covered with speckle painting, based on images captured by a CCD camera during a tensile test, or on images captured by an optical microscope after a test. With a DIC subset size of $13 * 13 \mu \mathrm{m}$, the mean axial strain measured in twin bands -relatively thick in single crystals, and made of alternating layers of twins and much less deformed matrix- was around $30 \%$. Converting this axial strain into a shear strain along the twinning direction, and using a "law of mixture", they estimated the twinned fraction in the band as $80 \%$. Yang et al. [29] used DIC to monitor twinning in a polycrystalline TWIP steel, based on images of samples covered with gold microgrids captured during in situ tensile tests in a SEM. The subset size for DIC was $4 \mu \mathrm{m}$. They developed a technique to monitor the evolution of the average twinned fraction in a grain, knowing its orientation, from preliminary EBSD mappings, and its mean axial and transverse plastic strains, from DIC.

In the present study, the same principles were used, but with an improved spatial resolution, allowing mappings of the twinned fraction over a whole grain (based on "point-wise" 
measurements, i.e. within $150 * 150$ to $250 * 250 \mathrm{~nm}$ areas), instead of providing only grainaveraged values. For that purpose, a dense and uniform distribution of gold nano-particles with a diameter of about $20 \mathrm{~nm}$ was laid on the polished surface of the specimens, by vapour-assisted remodelling of a $6 \mathrm{~nm}$ thick gold film during 3 hours at $200^{\circ} \mathrm{C}$. During the tests, the specimens were periodically unloaded to capture high-resolution images $(\approx 20 \mathrm{~nm} /$ pixel) of selected grains, used to compute the local in-plane plastic strains. The assumption of isochoric plastic deformation was adopted to compute the equivalent plastic strain.

The local values of longitudinal and transverse plastic strains $\left(\varepsilon_{p 11}\right.$ and $\left.\varepsilon_{p 22}\right)$ were extracted from the plastic strain maps and used to estimate the twin fraction in areas which exhibit a single set of parallel slip or twin lines.

Let $f^{t}$ denote the twin fraction on a twinning system $t, \gamma^{s}$ and $\gamma^{t}=f^{t} / \sqrt{2}$ the plastic shear strains produced by a slip and twinning systems, respectively, $R_{i j}=\frac{1}{2}\left(n_{i} m_{j}+n_{j} m_{i}\right)$ the orientation tensor of a slip or twinning system characterized by a plane normal $\vec{n}$ and a shearing direction $\vec{m}$. In the macroscopic frame, the local plastic strain can be written as the sum of slip and twinning systems contributions [30]:

$$
\varepsilon_{p i j}=\sum_{t} \frac{f^{t}}{\sqrt{2}} R_{i j}^{t}+(1-f) \sum_{s} \gamma^{s} \cdot R_{i j}^{s}
$$

If a single set of parallel slip or twin bands is visible in the area, the longitudinal and transverse components of the plastic strain tensor become, as a particular case of equation (1):

$$
\begin{aligned}
& \varepsilon_{p 11}=\frac{f}{\sqrt{2}} R_{11}^{t}+(1-f) \gamma^{s} \cdot R_{11}^{s} \\
& \varepsilon_{p 22}=\frac{f}{\sqrt{2}} R_{22}^{t}+(1-f) \gamma^{s} \cdot R_{22}^{S}
\end{aligned}
$$

Combining equations (2) and (3), the local twin fraction is found to be:

$$
f=\sqrt{2} \frac{\varepsilon_{p 11} \cdot R_{22}^{S}-\varepsilon_{p 22} \cdot R_{11}^{S}}{R_{11}^{t} \cdot R_{22}^{S}-R_{11}^{t} \cdot R_{11}^{S}}
$$

In some grains, in addition to parallel slip and twin traces, a second set of non-coplanar slip traces appeared. Considering the $\epsilon_{p 12}$ component of the plastic deformation tensor, also provided by DIC, gives (as another particular case of equation (1)) a third equation, which allows to take into account this second slip system.

$$
\begin{aligned}
& \varepsilon_{p 11}=\frac{f}{\sqrt{2}} R_{11}^{t}+(1-f)\left(\gamma^{s a} \cdot R_{11}^{s a}+\gamma^{s b} \cdot R_{11}^{s b}\right) \\
& \varepsilon_{p 22}=\frac{f}{\sqrt{2}} R_{22}^{t}+(1-f)\left(\gamma^{s a} \cdot R_{22}^{s a}+\gamma^{s b} \cdot R_{22}^{s b}\right) \\
& \varepsilon_{p 12}=\frac{f}{\sqrt{2}} R_{12}^{t}+(1-f)\left(\gamma^{s a} \cdot R_{12}^{s a}+\gamma^{s b} \cdot R_{12}^{s b}\right)
\end{aligned}
$$

The combination of equations (5) to (7) leads to a quadratic equation to calculate the local twin fraction.

A Matlab program was written to compute the twin fraction maps, based on the Euler angles of the grain, the crystallographic indices of the active slip/twinning plane (deduced from the angle of the slip/twin traces with respect to the tensile direction) and the indices of the twinning Burgers vector. The twin fraction map giving the most coherent results $(0<f<1)$ was kept and the systems forming this combination were considered activated. 


\subsection{Quantitative monitoring of twinning based on AFM images}

While nanotwins are nearly impossible to discriminate from planar slip bands in FCC metals based on optical, SEM images, or even from EBSD measurements that do not provide enough spatial resolution, their "topographic signature" at the surface of deformed samples is quite specific. This specificity is based on the uniform shear strain inside the twins which allows an unambiguous recognition on AFM images, especially "Amplitude Error" or "Peak Force Error" images that highlight the local slope of the surface. The emergence of a twin on a free surface induces a tilt by an angle $\theta(\gamma)$ which depends on the inclination angle $\beta$ of the twinning plane relative to the surface and the angle $\alpha$ between the twinning Burgers vector and the twin trace on the surface [15] :

$$
\tan \theta(\gamma)=\frac{\sin \alpha \cdot \sin ^{2} \beta}{\sqrt{2}+\sin \alpha \cdot \cos \beta \cdot \sin \beta}
$$

A Matlab program was written to determine the twinning plane, based on the Euler angles of the grain and the orientation of the twin lines, and to compute angle $\beta$ and the 3 values of angle $\alpha$ corresponding to the three possible twinning Burgers vectors. Three possible values of $\theta(\gamma)$ were thus obtained using equation (8), among which the angle closest to the measured surface tilt angle on AFM profiles, was chosen. Then the intercept method proposed by Koyama et al. [15] was used to deduce the line fraction $f^{t}$ of twins in the grain of interest. The widths $w_{i}$ of intercepted twins were measured (and averaged) along several parallel AFM profiles of length $L$ normal to the twins, taking into account the necessary correction for the tilt of the surface, one gets [15]:

$$
f^{t}=\sum_{i}\left(1-\frac{\tan \theta(\gamma)}{\tan \beta}\right) \frac{w_{i}}{L}
$$

Thus, over one cycle, the variation $\Delta f^{t}$ of the line fraction of twins was calculated as:

$$
\Delta f^{t}=\sum_{i}\left(1-\frac{\tan \theta(\gamma)}{\tan \beta}\right) \frac{\Delta w_{i}}{L}
$$

where $\Delta w_{i}$ is the variation of the width of the twin $i$ during one cycle. Applying the plastic deformation kinematics equation (1) over one cycle, the amplitude of plastic deformation accommodated by twinning/detwinning is expressed as :

$$
\Delta \varepsilon_{p i j}^{t}=\sum_{t} R_{i j}^{t} \cdot f^{t} \cdot \gamma^{t}
$$

The amplitude of the axial plastic deformation accommodated by twinning/detwinning, if one or two twinning systems are considered, is thus expressed, as particular cases of equation (11) as:

$$
\begin{gathered}
\Delta \varepsilon_{p 11}^{t}=R_{11}^{t} \cdot \frac{f^{t}}{\sqrt{2}} \\
\Delta \varepsilon_{p 11}^{t}=R_{11}^{t 1} \cdot \frac{f^{t 1}}{\sqrt{2}}+R_{11}^{t 2} \cdot \frac{f^{t 2}}{\sqrt{2}}
\end{gathered}
$$

\section{Experimental observations}

HR-DIC was first used to detect the onset of mechanical twinning in favorably oriented grains, and to validate this twin-detection technique by comparison with a post-test EBSD mapping, before applying it to reversed loading.

\subsection{Monitoring of the onset of twinning in tension in a SEM, using HR-DIC}

Figures $4(a)$ to (d) show the equivalent plastic strain field inside a grain with a near (111) orientation (grain \#1 in table 3, Appendix) for increasing values of the macroscopic axial plastic strain. Figures $4(\mathrm{e})$ to $(\mathrm{h})$ show the corresponding equivalent plastic strain profiles along the white dashed line, in figure $4(\mathrm{~b})$. Until a macroscopic plastic strain of $1.98 \%$, the field was relatively 
homogeneous and its largest value did not exceed 5\%. A thin band appeared after $2.6 \%$ of plastic strain (denoted below as $t_{1}$ ) and from the trace analysis could correspond to the $(\overline{1} 1 \overline{1})[21 \overline{1}]$ system with a Schmid factor of 0.38 (see table 3, Appendix). One of the band tips is observed to meet a triple point. Upon further straining, additional parallel thin bands (denoted $t_{2} t_{6} t_{6}$ ), associated with sharp peaks of $\varepsilon_{\text {peq }}$, appeared and the intensity of existing peaks increased while the background equivalent plastic strain level in the surrounding matrix remained low.

After 4.5\% plastic strain, an additional set of high plastic strain bands (marked 2 on figure 4(b)),

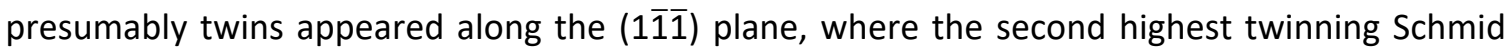

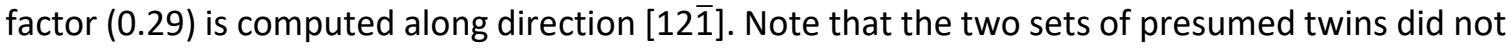
cross each other.

An EBSD mapping of crystal orientation in this grain performed after the test (with a stepsize of $50 \mathrm{~nm}$ and an acceleration voltage of $15 \mathrm{kV}$ ) confirmed that both sets of high strain bands are actually twins (Figure 5(a)). However, because of a lack of spatial resolution, EBSD fails to detect those of the twin bundles $\left(t_{3}, t_{4}\right.$ and $\left.t_{6}\right)$ where the equivalent plastic strain is less intense, contrary to HR-DIC. A careful look at figure $5(\mathrm{a})$ reveals dark lines along part of "twin bundles $t_{3}, t_{4}$ and $t_{6}$ ". In the literature on TWIP steels, such dark lines (in which the misorientation is too high and localized to allow a proper indexation, which is not the case in slip bands at such modest macroscopic strains) on the band contrast or Kikuchi Pattern Quality map are often reported [14, 31,32 ] as twin bundles, yet too thin to be succesfully indexed. Furthermore, in the present case, they are close and parallel to the successfully indexed twin bundles, $t_{1}, t_{2}$ and $t_{5}$. Note that even the latter are not completely indexed over their whole length, because the bundles do not have a uniform thickness along their length. This, added to the very large equivalent plastic strain in $t_{3}$, $t_{4}$ and $t_{6}$ (Figure 4(h)) makes us confident that these are also twin bundles. HR-DIC thus might be a more sensitive twin detection technique than EBSD. 

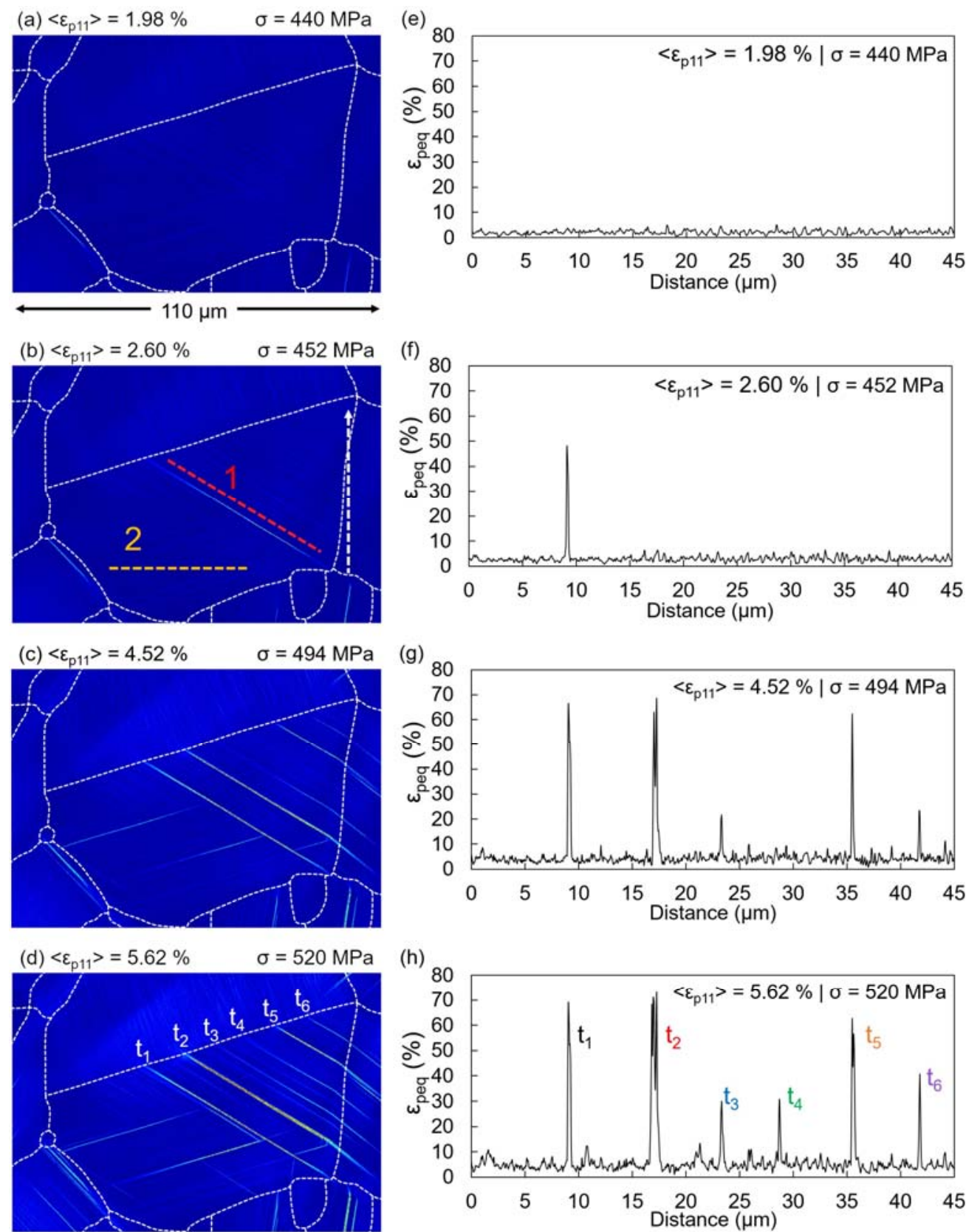

Figure 4: In situ tensile test in the SEM. (a) - (d) Evolution of the equivalent plastic strain field in grain \#1 with a (111) orientation and (e) - (h) evolution of the equivalent plastic strain profile along the white dashed line in figure $4(\mathrm{~b})$, for : (a), (e) $\left\langle\varepsilon_{p 11}\right\rangle=1.98 \%$; (b), (f) $\left\langle\varepsilon_{p 11}\right\rangle=2.60 \%$; (c), (g) $\left\langle\varepsilon_{p 11}\right\rangle=4.52 \%$ and (d), (h) $<\varepsilon_{p 11}>=5.62 \%$

A consistent estimate of the local twin fraction on the $(\overline{1} 1 \overline{1})[21 \overline{1}]$ system was obtained considering dislocation glide on the $(\overline{1} 1 \overline{1})[\overline{1} 01]$ parallel slip system and on the $(1 \overline{1} \overline{1})[0 \overline{1} 1]$ noncoplanar slip system.

Figure $5(b)$ shows the evolution of the local twin fraction at the positions of the bands $t_{1}$ to $t_{6}$ along the white line plotted in figure $4(\mathrm{~b})$. A twin fraction below $10-15 \%$ is not considered meaningful, since it can be due to noise in plastic strain measurement. However, the stress range for which a sharp rise above this threshold first occurs (for twin $t_{1}$ in the present grain) represented by the dashed yellow box in figure $5(\mathrm{~b})$, was considered as the tensile stress range for the onset of twinning.

Table 2 summarizes the stress range at the onset of twinning $\left(\sigma_{T}\right)$ estimated in the same way in five monitored grains. The values spread between 400 and $475 \mathrm{MPa}$. The corresponding apparent critical resolved shear stress (CRSS) is not constant, which means that the stress field cannot be considered as uniform. 

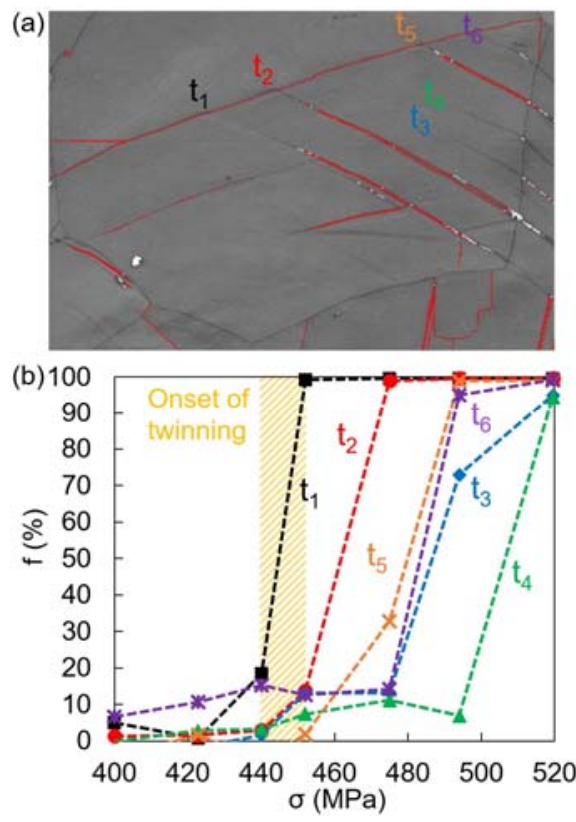

Figure 5: In situ tensile test in the SEM. (a) Band contrast map of the grain \#1 at $\left\langle\varepsilon_{p 11}\right\rangle=5.62 \%$ with twin boundary plotted in red and (b) evolution of the twin fraction at the position of bands $t_{1}$ to $t_{6}$ along the white line in figure $4(\mathrm{~b})$

\section{Table 2}

In situ tensile test in the SEM. Grain size, stress range at the onset of twinning $\left(\sigma_{T}\right)$ with corresponding twinning Schmid factor (SF), apparent critical resolved shear stress $\left(\tau_{T}\right)$ and macroscopic axial plastic strain $\left(<\varepsilon_{p 11}>\right)$

\begin{tabular}{llllll}
\hline Orientation & $\mathrm{SF}$ & Grain size $(\mu \mathrm{m})$ & $\sigma_{T}(\mathrm{MPa})$ & $\tau_{T}(\mathrm{MPa})$ & $<\varepsilon_{p 11}>(\%)$ \\
\hline$(111)$ & 0.37 & 112 & $400-423$ & $148-156$ & $0.55-1.37$ \\
$(111)$ & 0.38 & 79 & $440-452$ & $165-170$ & $1.98-2.60$ \\
$(111)$ & 0.39 & 107 & $440-475$ & $170-184$ & $1.98-3.49$ \\
$(101)$ & 0.49 & 94 & $400-440$ & $196-215$ & $0.55-1.98$ \\
$(101)$ & 0.47 & 80 & $423-452$ & $201-214$ & $1.37-2.60$ \\
\hline
\end{tabular}

\subsection{Monitoring of twinning/detwinning in tension-compression in a SEM}

As mentioned in the introduction, a comprehensive investigation of the macro-scale cyclic plasticity of this TWIP steel, with TEM observations has been run [18] in parallel with the present micro/nano-scale study based on in situ tests. The TEM observations revealed a limited fraction of twinned grains after the tests run at a plastic strain range smaller than $\pm 0.5 \%$, or a stress range smaller than $\pm 500 \mathrm{MPa}$. On the one hand, to be able to document twinning/detwinning, the in situ tests had to be run at least at these amplitudes. On the other hand, the load capacity of the in situ testing machine, and the risk of sample buckling in compression limited the allowable loading range. As for the choice of the backstrain, fully reversed loadings were applied, like in the macro-scale study.

A few grains, in which twinning was expected either in tension or in compression, were monitored with HR-DIC during one tension-compression cycle and a half at a constant stress amplitude $\Delta \sigma / 2=475 \mathrm{MPa}$.

Figure 6(a) shows the equivalent plastic strain field in a grain with a near (101) orientation (grain \#2 in table 3) after the first tension to $475 \mathrm{MPa}$, and figure 6(b) shows enlargements of the yellow box at various steps, to highlight the evolutions in the local equivalent plastic strain as the tensile stress first increases, and then goes into compression and back to tension. The twin fraction was computed (as shown by the yellow box in figure 6(a)) along the intense plastic strain band that appeared at $400 \mathrm{MPa}$ along the (1)11) plane, considering only the contribution of the 
[2111] twinning system with a Schmid factor of 0.44 , only hypothesis giving consistent results in that case.

Figure 6(c) shows the evolution with the applied stress of the twin fraction along the deformation band during one cycle and a half. The relation between the applied stress and the twin fraction averaged over the first $10 \mu \mathrm{m}$ of the profiles (yellow dashed box in figure $6(\mathrm{c})$ ), where the evolution are more pronounced, is presented in figure $6(d)$.

During the first tensile ramp (denoted as te ${ }_{1}$ ), $<f>$ increased from $10 \%$ at $400 \mathrm{MPa}$ to $37 \%$ at $475 \mathrm{MPa}$, while during the subsequent compression $\left(c_{1}\right),\langle f>$ decreased to $33 \%$ and finally to $22 \%$. During the second tension $\left(\mathrm{te}_{2}\right),<f>$ remained nearly constant until $450 \mathrm{MPa}$, and then increased to $25 \%$. A clear mechanical hysteresis of the twinned fraction was thus observed. Detwinning and retwinning were only partially achieved. Moreover, the stress for the onset of detwinning was found, in absolute value, to be nearly equal to the one for twinning and retwinning.
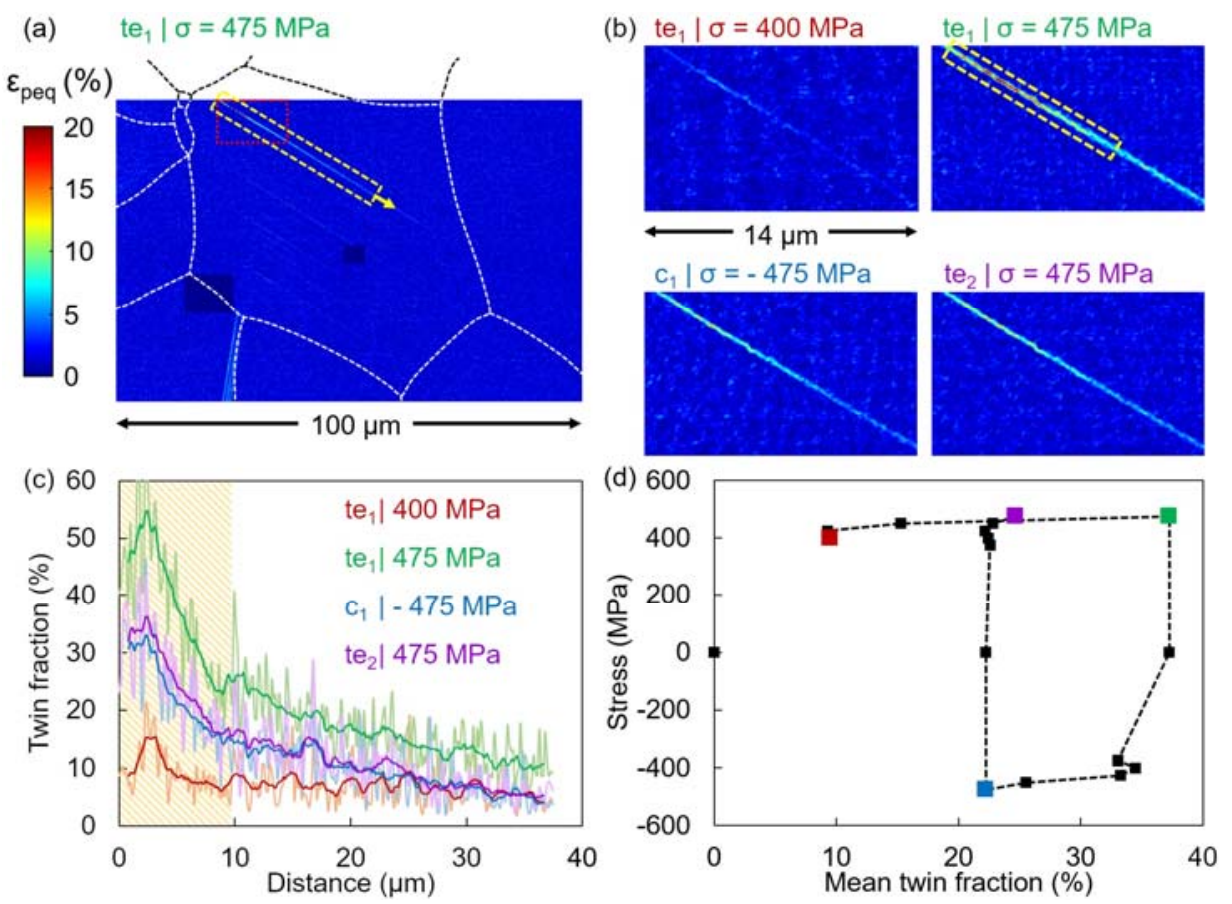

Figure 6: In situ tension-compression test in the SEM. (a) Equivalent plastic strain field in grain \#2 with a near (101) orientation after the first tension to $475 \mathrm{MPa}$, (b) enlargements of the yellow box in (a) at various steps, (c) evolution of the twin fraction during one cycle and a half along the yellow box in (a) and (d) stress versus twin fraction averaged over the first ten microns of the profiles (yellow dashed area in (c)). Given the noise on the measured plastic strains, a moving average was superimposed to the raw local data

The local twin fraction was also calculated in grain \#3 with a near (001) orientation, where

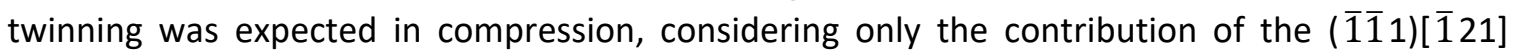
twinning system, with a Schmid factor of -0.49 (Figure $7(a)$ ). Figures $7(b)$ and (c) show the evolution of the twin fraction along the twin bundles denoted as $t_{2}$ and $t_{3}$, while figure $7(d)$ shows the evolution with the applied stress of the mean twin fraction over the twins $t_{1}$ to $t_{3}$. After their nucleation at $-375 \mathrm{MPa}$, the twin fraction in the three twin bundles did not increase during the remaining of the compression segment $\left(c_{1}\right)$. During the second tensile ramp $\left(\mathrm{te}_{2}\right)$, a $14 \%$ drop in twin fraction occurred at $375 \mathrm{MPa}$ in twin $t_{3}$, while the drop was only by $6 \%$ in twin $t_{1}$, and the twin fraction along $t_{2}$ remained constant. It can then be concluded that detwinning of parallel twins in a grain is not similar, and seems to be controlled by very local factors.

The HR-DIC procedure in the SEM is efficient, but requires a lot of SEM time (not to mention the image post-treatment and correlation time), so that these observations could not be continued. Fortunately, the twinning activity could be more conveniently monitored at length, during tens or hundreds of tension-compression cycles through in situ tests under an AFM, using the specific surface topography induced by twinning, as presented below. 

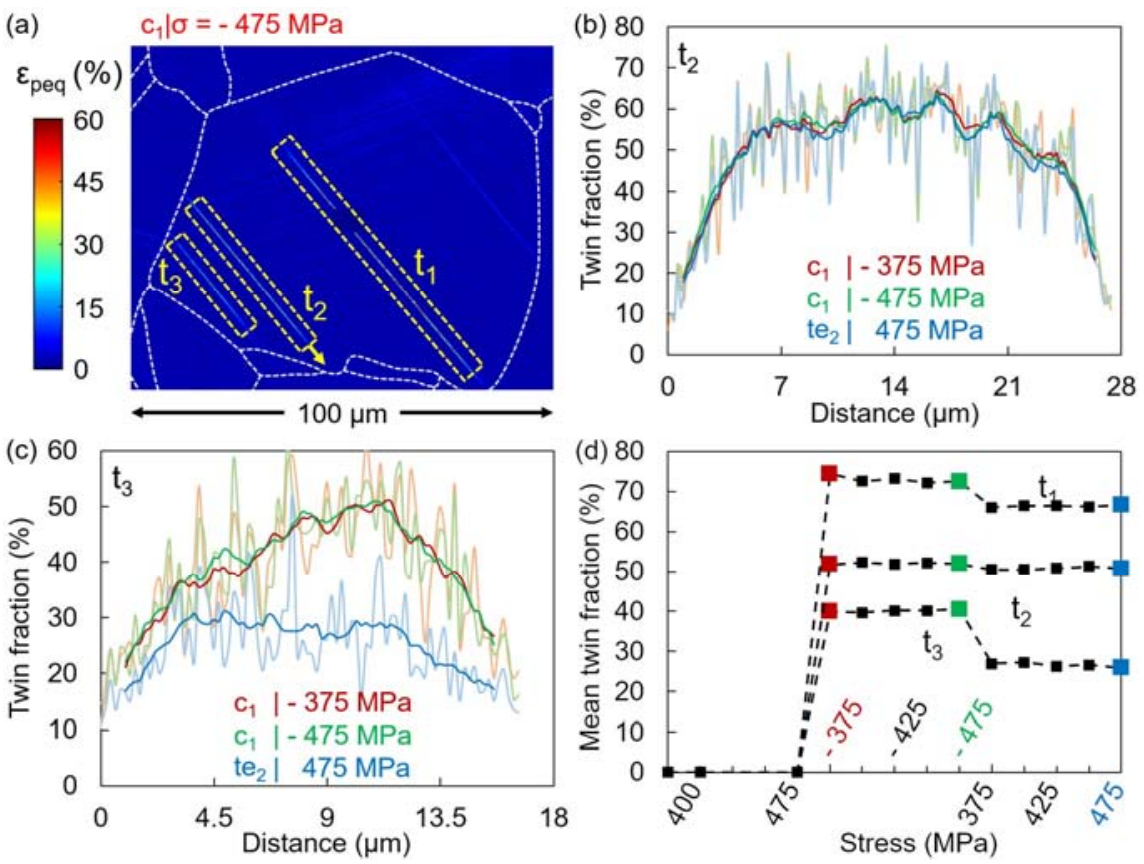

Figure 7: In situ tension-compression test in the SEM. (a) Equivalent plastic strain field in grain \#3 with a near (001) orientation after the compression to $-475 \mathrm{MPa}$, (b) evolution of the twin fraction along $t_{2}$ and (c) $t_{3}$. (d) Evolution of the mean twin fraction over the twins $t_{1}$ to $t_{3}$ with the applied stress

\subsection{Monitoring of twinning/detwinning in tension-compression under an AFM}

Figures 8(a) and (b) show optical images of grain \#4 with a near (123) orientation (see table 3), captured after tension up to $574 \mathrm{MPa}$ and subsequent compression down to $-522 \mathrm{MPa}$, respectively. Figures 8 (c) and (d) show the corresponding Peak Force error images of the $30 \times 30$ $\mu \mathrm{m}^{2}$ area indicated by red squares on the previous ones, and figures $8(\mathrm{e})$ and $8(\mathrm{f}) 3 \mathrm{D}$ images of the same areas, illustrating the formation and recession of a saw-tooth topography, in tension and compression, respectively. These images have 512 × 512 pixels, corresponding to in-plane resolution of $58 \mathrm{~nm}$. The direction of the bright lines on figures $8(\mathrm{c})$ and (d) matches with the trace of the $(\overline{1} 1 \overline{1})$ plane and the twinning system with the highest Schmid factor $(0.48)$ in the grain.

Figure $8(\mathrm{~g})$ shows the evolution, upon stress reversal, of the topographic section along the white box in figure 8 (c) and (d). The topography was averaged over the $5 \mu \mathrm{m}$ width of the box to reduce the artefacts due to some OPU and OPS particles left by polishing on the surface. After tension up to $574 \mathrm{MPa}$, a sawtooth profile, with 25 and $60 \mathrm{~nm}$ high peaks appeared. Their emergence angle, between 14 and $16^{\circ}$, matches well with the angle of $14.7^{\circ}$ predicted by equation (8). The white bands denoted as $t_{1}$ to $t_{5}$ are thus nanotwins formed on the $(\overline{1} 1 \overline{1})[\overline{1} 12]$ system, with a Schmid factor of 0.48 , which is the highest in grain \#4.

Upon stress reversal, a progressive decrease of the twins height is observed. Figure $8(\mathrm{~h})$ shows that this decrease had begun before $-417 \mathrm{MPa}$ for $t_{1}, t_{3}$ and $t_{4}$. Upon further compression, the decrease in height of all the twins accelerated, and twins $t_{1}$ and $t_{3}$ almost completely disappeared at $-522 \mathrm{MPa}$. 

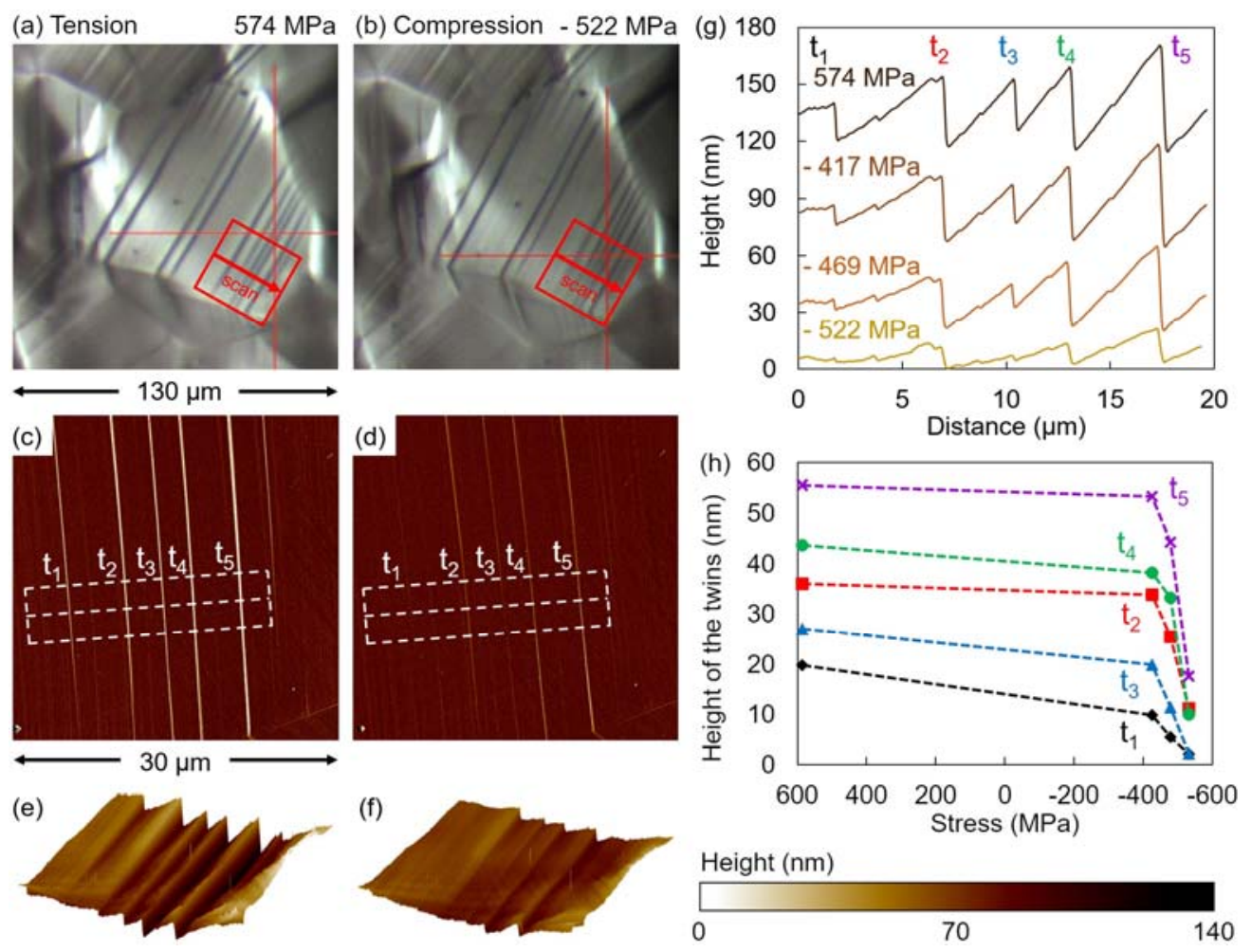

Figure 8: Stress-controlled in situ tension-compression test under the AFM. (a)-(b) Optical images, (c)-(d) Peak Force Error images and (e)-(f) 3D images of the zone in the red square in (a) and (b) of the grain \#4 with a near (123) orientation after: (a), (c), (e) tension up to $574 \mathrm{MPa}$ and (b), (d), (f) subsequent compression to $-522 \mathrm{MPa}$. (g) Evolution of the topography along the white boxes in (c) and (d). (h) Evolution of $t_{1}$ to $t_{5}$ twins heights with the applied stress

An in situ tension-compression test was carried out under AFM with a constant stress amplitude of $\Delta \sigma / 2=511 \mathrm{MPa}$, and a frequency of $4^{*} 10^{-3} \mathrm{~s}^{-1}$. Cycling was regularly stopped to image the few monitored grains (grains \#5 to \#9 in table 3 ) at peak tension and subsequent peak compression. According to a preliminary macro-scale test run on a cylindrical specimen equipped with an extensometer, at nearly the same stress amplitude (Figure 9(a)), the first tension segment, induces nearly $5 \%$ monotonic plastic strain. The plastic strain range first decreases during 125 cycles, denoting cyclic hardening (see figure 9 (b) and the shrinkage of the stress-strain loops), and then starts increasing, denoting cyclic softening. To monitor twinning/detwinning activity during both stages, AFM observations were made at cycles 1, 2, 20 and 100 (hardening stage) as well as 500 and 700 (softening stage).

Figures 10(a) and (b) show the peak force error images and figures 10(c) and 10(d) 3D images of a portion of grain \#5 (Table 3) with a near (124) orientation at peak tensile and compressive stresses, during the first cycle. The $5 \%$ monotonic plastic strain during the first tension segment was accompanied by the nucleation of three large twin bundles, denoted as $t_{1}$ to $t_{3}$ from left to right, with an apparent thickness of 620, 240 and $290 \mathrm{~nm}$, and a height of 153, 42 and $59 \mathrm{~nm}$. The agreement between their emergence angle $\left(15-16^{\circ}\right)$ and the expected one $\left(16.3^{\circ}\right)$ for the twinning system $(1 \overline{1} \overline{1})[1 \overline{1} 2]$ with the maximum Schmid factor $(0.46)$ in the grain was verified. It should also be noted that an enhanced plastic activity seems to be triggered in the neighboring grains, close to the point where the twins hit the grain boundary.

During the subsequent compression, total detwinning of $t_{2}$ and partial detwinning of $t_{1}$ and $t_{3}$ was observed. This phenomenon is better highlighted in figure 10(e) which displays the topographic evolution, along the yellow dashedbox in figure 10(a) and (b), between the tension peak and the subsequent compression peak of the $1^{\text {st }}$ cycle. The evolution of the topography within the $2^{\text {nd }}$ cycle (Figure 10(f)) was much less pronounced than within the first one, and it was even smaller within further cycles. While twins $t_{1}$ and $t_{3}$ regained some height during the $2^{\text {nd }}$ tension, twin $t_{2}$ did not, but a new twin was formed nearby. The precise observation of the 
evolution of $t_{1}$ in figure $10(\mathrm{~g})$ during the $1^{\text {st }}$ and $2^{\text {nd }}$ cycle and 2 nd cycle gives a more visual proof of the partial detwinning/retwinning processes reflected by $t_{1}$ becoming alternatively more or less pronounced after tension and compression peaks respectively.
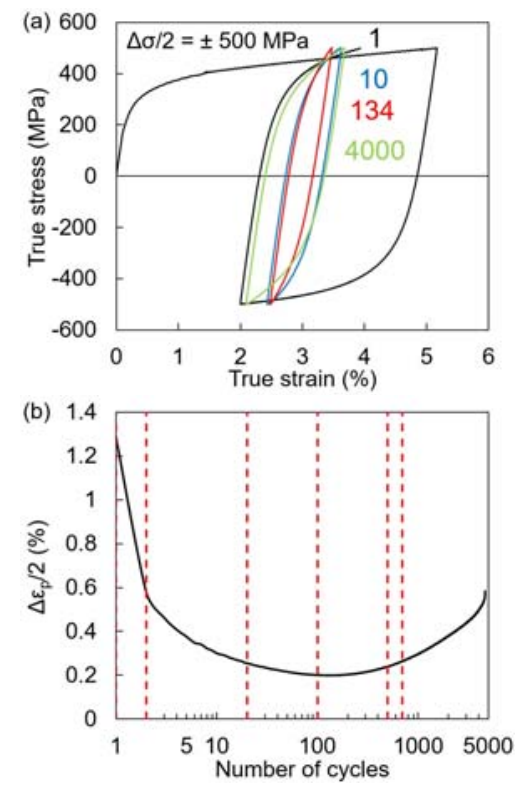

Figure 9: (a) Evolution of the true stress - true strain loops with cycling and (b) evolution of the plastic strain range at $\Delta \sigma / 2=500 \mathrm{MPa}$. The vertical dotted lines indicate AFM image captures.
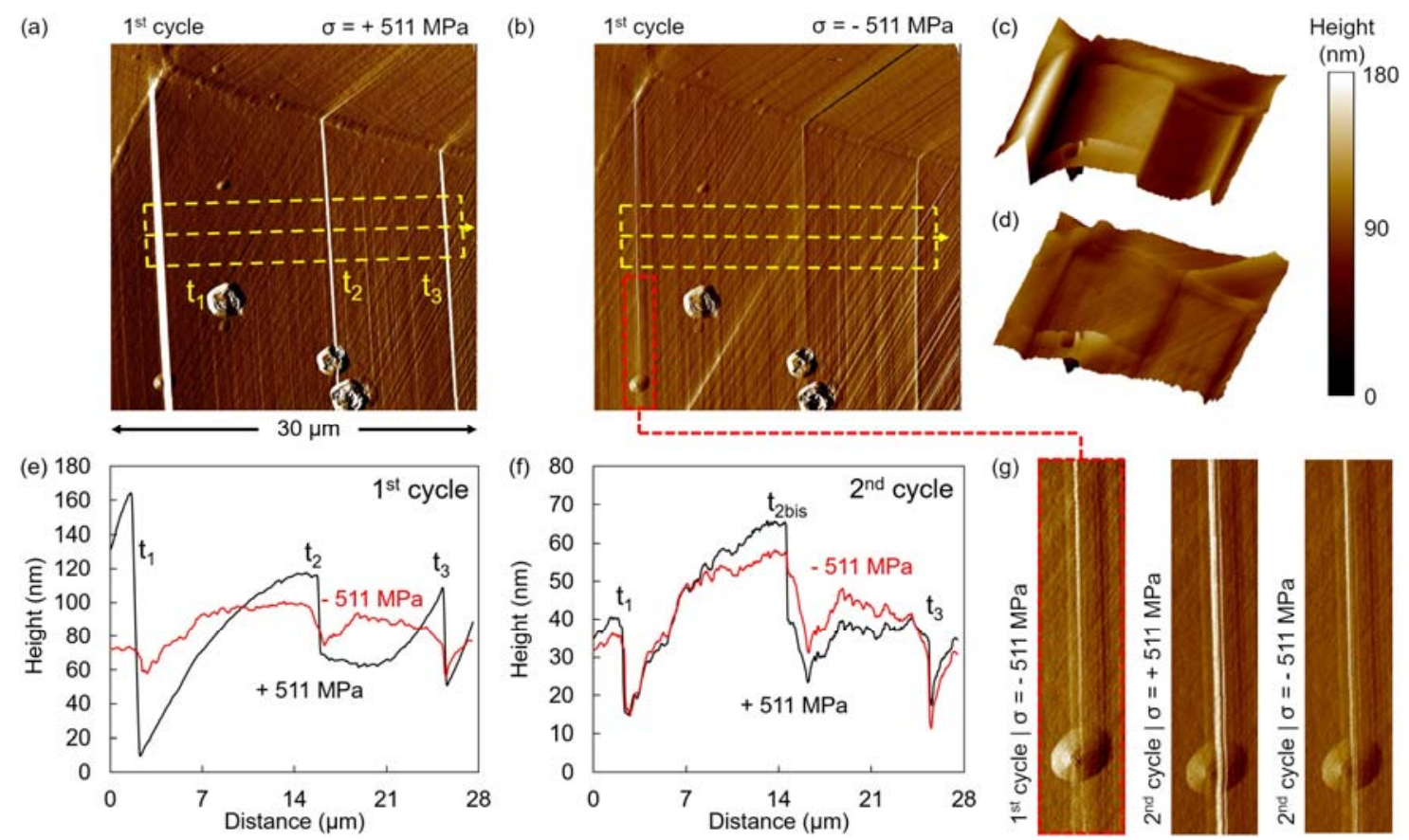

Figure 10: Stress-controlled in situ tension-compression test under the AFM : (a)-(b) Peak Force Error images and (c)-(d) 3D images of a zone of the grain \#5 during the $1^{\text {st }}$ cycle after: (a), (c) tension up to $511 \mathrm{MPa}$ and (b), (d) subsequent compression to $-511 \mathrm{MPa}$. (e) Evolution of the topography during the $1^{\text {st }}$ cycle and (f) the $2^{\text {nd }}$ cycle along the yellow dashed box in (a) and (b). (g) Enlargements of the red box in (b) at various cycles

While grain \#5 exhibited twinning only in tension and partial detwinning in compression, AFM scanning with an in-plane resolution of 20 to $30 \mathrm{~nm} /$ pixel allowed the detection in some grains of twins nucleated both in tension and in compression along the same plane. Indeed, in grain \#8 two types of parallel bands with an opposite slope appeared during the $1^{\text {st }}$ cycle. Those that appeared in tension with an emergence angle of $13-15^{\circ}\left(t_{1}\right.$ to $t_{4}$, on figure $\left.11(a)\right)$, looking clearer than the 
matrix, were identified as (111)[11ㄹ] twins (expected angle : $13^{\circ}$, Schmid factor of 0.45 ), and the one that appeared in compression ( $c_{1}$ to $c_{3}$ ) looking darker than the matrix, were identified as (111) $[\overline{2} 11]$ twins, with a Schmid factor of -0.37 . It therefore seems that a given grain can accommodate plastic deformation in both tension and compression by twinning/detwinning on a single system, and/or by twinning on the same plane, in two different shearing directions inducing axial plastic flow in opposite directions. By contrast, load reversals were not observed to trigger twinning on non-coplanar systems.
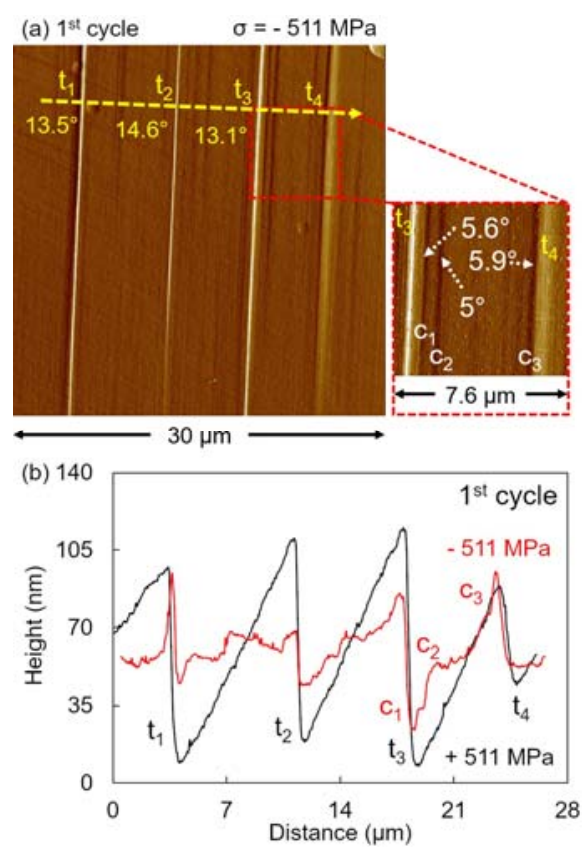

Figure 11: Stress-controlled in situ tension-compression test under the AFM. (a) Peak Force Error image of grain \#8 captured at the end of the $1^{\text {st }}$ cycle and (b) evolution of the topography along the yellow dashed line in (a) during the $1^{\text {st }}$ cycle

Figure 12(a) shows the evolution of the linear twin fraction calculated with equation (9) along profiles drawn perpendicularly to the primary twinning system in a zone of about $30 * 30 \mu \mathrm{m}^{2}$ of the monitored grains ( $\# 5$ to $\# 9$ in table 3 ). The results are plotted versus the number of half-cycles, to highlight the evolutions within each cycle. In these grains and under loading conditions, the linear twin fraction shows significant variations only during the first two cycles and then tends to stabilize.

The plastic strain amplitude accommodated by twinning/detwinning within each cycle, calculated with equation (12) or (13), was plotted on figure 12(b). The amplitude is significant during the $1^{\text {st }}$ cycle, during which it reaches 0.5 to $1.4 \%$, but then it gradually decreases down to values between 0.005 and $0.05 \%$ at the $100^{\text {th }}$ cycle, depending on the grain, and stays almost constant around $0.05 \%$ afterwards in grain \#5, the only one monitored at this stage.

Another tension-compression test was carried out under the AFM with a constant plastic strain amplitude $\Delta \varepsilon_{p} / 2=0.5 \%$ (see 2.2). Figure 13 shows the evolution of the peak tension and compression stresses recorded during a preliminary macroscopic cyclic test on a cylindrical specimen, and then applied on the sample during the in situ test. Four grains (\#10 to \#13 in table 3) were scanned within specific cycles (red dashed lines in figure 13) at peak tension and subsequent peak compression. In addition, a $300 * 300 \mu \mathrm{m}^{2}$ area containing nearly 100 grains was also monitored at each of these cycles, after unloading from compression. This monitoring was performed by stitching $60 * 60 \mu \mathrm{m}^{2}$ images (with a resolution of $30 \mathrm{~nm} /$ pixel) obtained by automated stage movements and AFM scans. 

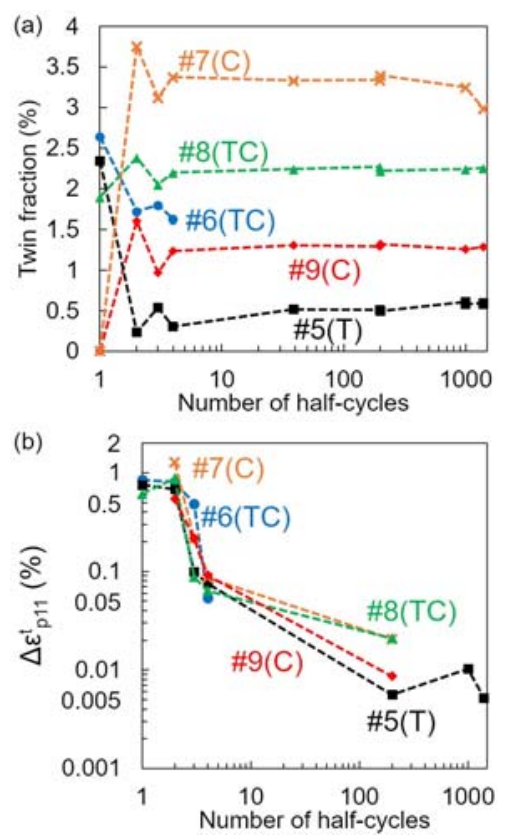

Figure 12: Stress-controlled in situ tension-compression test under the AFM. (a) Evolution of the linear twin fraction and (b) of the amplitude (log scale) of the axial plastic deformation accommodated by twinning/detwinning within each cycle in the monitored grains during the cyclic plasticity under tensioncompression at $\Delta \sigma / 2=511 \mathrm{MPa}$. Letters $\mathrm{T}, \mathrm{C}$ and $\mathrm{TC}$ indicate respectively grains in which twinning was activated in tension, in compression or in tension and compression along the same twinning plane.

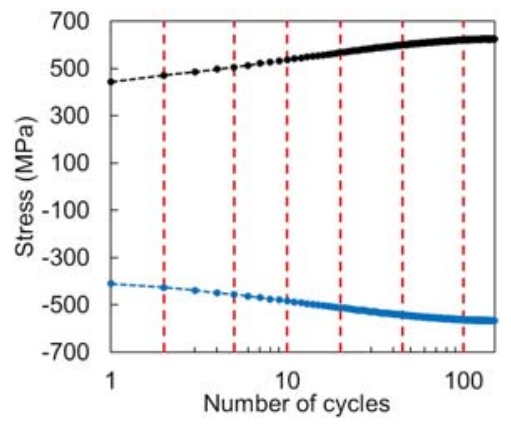

Figure 13: Evolution of the peak tension and compression stresses recorded during a macro-scale tensioncompression test at $\Delta \varepsilon_{p} / 2=0.5 \%$ and applied during an in situ cyclic test under the AFM

Figure 14(a) shows the presence of two twin families during the first compression down to $411 \mathrm{MPa}$ in different areas of grain \#10 with an orientation close to (001) (see table 3) : one with an emergence angle of 10 to $12^{\circ}$ corresponding with the angle of $11.4^{\circ}$ expected for $(\overline{1} 1 \overline{1})[\overline{1} \overline{1} \overline{1}]$ twinning system ( $S F=-0.46$, twins $t_{1}$ and $\left.t_{2}\right)$, and the other, with an emergence angle of 3 to $5^{\circ}$, matching with the angle of $3.2^{\circ}$ expected for $(\overline{1} 11)[\overline{1} 21]$ system $(\mathrm{SF}=-0.50)$. Figure $14(\mathrm{c})$ shows the evolution of $t_{1}$ and $t_{2}$ twins height during subsequent cycles. Both twins exhibit successive partial detwinning/retwinning cycles. Their height progressively increases, following a ratchetting evolution, which seems to slow down and to saturate, as the rise of the stress range does (Figure 13). While the number of twins hardly increased during the next 100 cycles on the $(\overline{1} 1 \overline{1})[\overline{1} \overline{2} \overline{1}]$

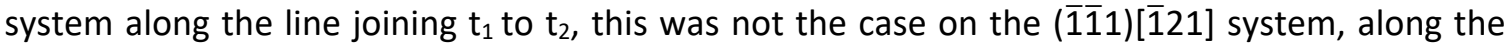
yellow box plotted on figures 14(a) and (b), as shown by figure 14(d). The mean height of the twins formed during the first cycle did not rise, and even slightly decreased, but numerous thin new twins progressively appeared throughout cyclic hardening. 
(a)
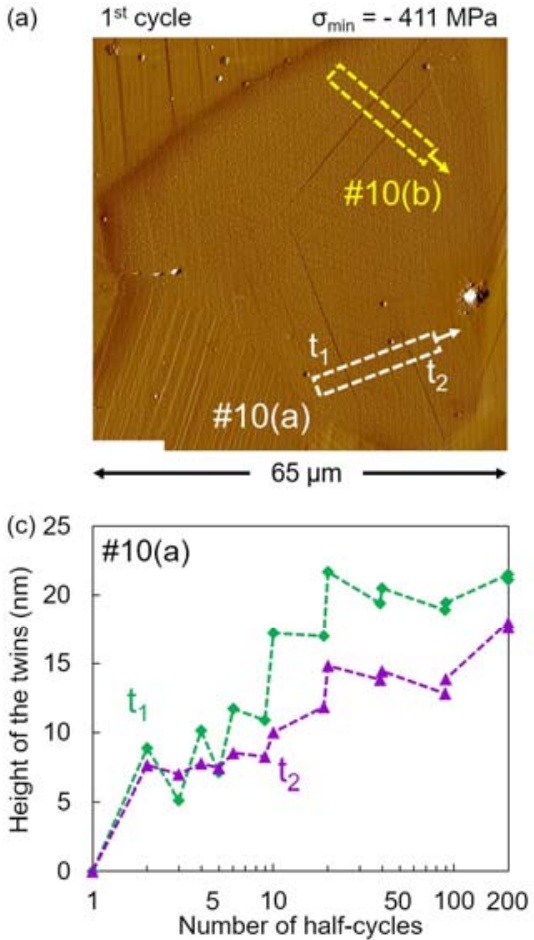

(b)
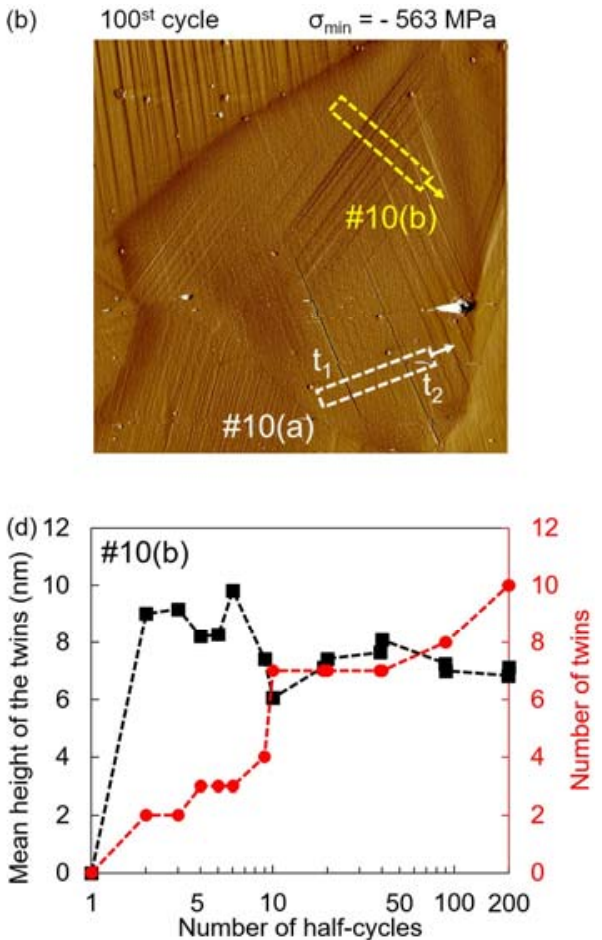

Figure 14: Plastic strain-controlled in situ tension-compression test under the AFM at $\Delta \varepsilon_{p} / 2=0.5 \%$. (a) Peak force error images of grain \#10 after the first compression down to $-411 \mathrm{MPa}$ and (b) after compression down to $-563 \mathrm{MPa}$ during the $100^{\text {th }}$ cycle. (c) Evolution of $t_{1}$ and $t_{2}$ twins height and (d) evolution of the average twins height and number of twins along the yellow box on figures 14(a) and 14(b)

The linear twin fraction (Equation (9)) and the plastic strain amplitude accommodated by twinning/detwinning (Equation (12) or (13)) in grain \#10 and three other grains are shown in figures 15(a) and (b), respectively.
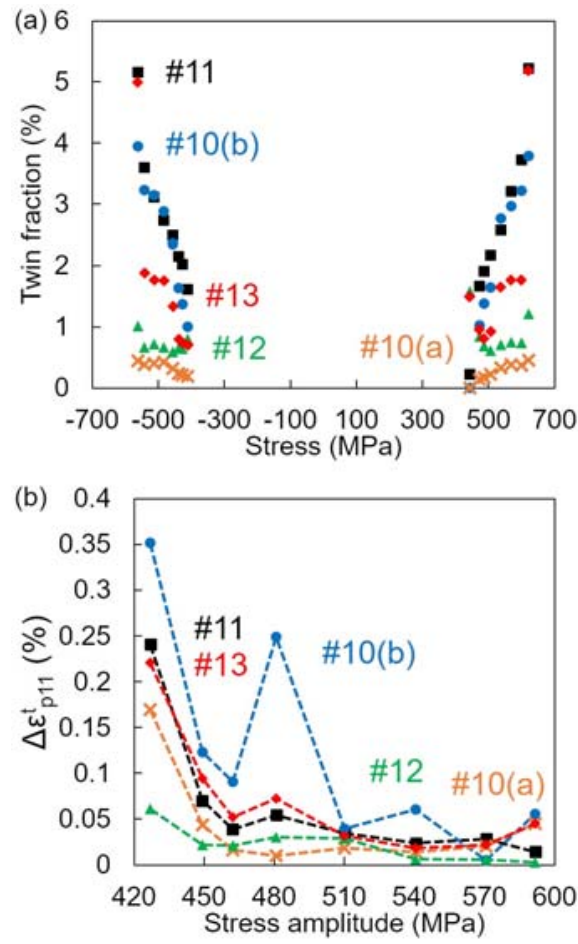

Figure 15: Plastic strain-controlled in situ tension-compression test under the AFM at $\Delta \varepsilon_{p} / 2=0.5 \%$. (a) Evolution of the linear twin fraction with peak tension and compression stress and (b) of the amplitude of the axial plastic deformation accommodated by twinning/detwinning within each cycle with the stress amplitude during cyclic hardening 
The twin fraction increased with the applied stress in all the monitored grains. While twinning could accommodate 0.06 to $0.42 \%$ plastic deformation during the first tensile ramp, twinning/detwinning accommodated 0.06 to $0.35 \%$ plastic strain range during the first stress reversal, when the stress amplitude was still rather low $(\Delta \sigma / 2=426 \mathrm{MPa})$. With further cycling, the plastic amplitude accommodated by twinning/detwinning gradually decreased, despite the increase of the stress amplitude, and reached a steady state value between 0 and $0.05 \%$. Therefore, the ratchetting increase of the twin fraction during cyclic hardening seems to be accompanied by a decay of the oscillation amplitude of the twin fraction within each cycle.

Since some bands were too thin with respect to the in-plane resolution to be identified unambiguously as twins by their emergence angle in the $300 * 300 \mu \mathrm{m}^{2}$ zone, a qualitative criterion was adopted. Only bands with a homogeneous contrast and crossing the whole grain were considered as twins. Moreover, two twinning systems were considered activated on planes with both clear and dark bands. Figure 16(a) shows that the mean number of activated twinning planes and twinning systems per grain increased continually during cyclic hardening. After the $100^{\text {th }}$ cycle $\Delta \sigma / 2=592 \mathrm{MPa}$ ) they were 1.15 and 1.4 , respectively. Interestingly, the mean number of twinning systems activated per plane remained almost constant (1.25) throughout the whole cyclic hardening stage. Figure 16 (b) shows that the number of activated twinning systems remained low and almost constant ( 0.3 to 0.4 ) in the smallest grains $(\mathrm{d}<20 \mu \mathrm{m}$ ) while it increased during the whole cyclic hardening stage, from 1.6 to 2.1 , in the largest grains ( $d>60 \mu \mathrm{m}$ ).
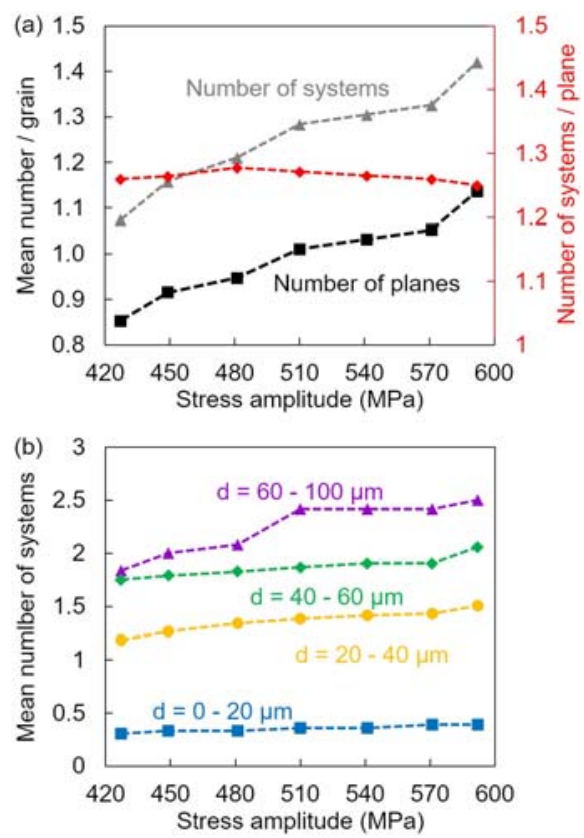

Figure 16: Plastic strain-controlled in situ tension-compression test under the AFM at $\Delta \varepsilon_{p} / 2=0.5 \%$. (a) Evolution of the mean number of twinning planes and twinning systems activated per grain and of the mean number of twinning systems activated per plane with the stress amplitude and (b) effect of the grain size on the mean number of twinning systems activated per grain

\section{Discussion}

\subsection{Onset of twinning}

Twin nucleation is a very dynamic phenomenon, able to induce stress drops in Cu-8.5Al single crystals [9] or acoustic emission in some metals, like Zinc. The ongoing nucleation of new twins (that is : the stage between the controversial dislocations reactions leading to a twin embryo and the moment where a fully formed nanotwin is present, and often crosses a whole grain) cannot be resolved by SEM or AFM imaging, whose spatial resolution is high, but whose time resolution is poor, and that, furthermore, are used at discrete moments during in situ tests. This is also probably the case for ongoing detwinning. What these techniques can detect is a resulting rise or fall in the local twin fraction, after these dynamic steps are achieved. 
The CRSS for twinning has however been estimated, from in situ tensile tests with SEM-imagesbased HR-DIC, between 148 and $215 \mathrm{MPa}$. The values can be compared to analytical expressions of the CRSS for twinning $\left(\tau_{t}\right)$ issued from different twin nucleation models. According to the polar model proposed by Venables, $\tau_{t}$ is expressed as [33] :

$$
\tau_{t}=\frac{\gamma_{S F}}{b_{p}}+\frac{G b_{p}}{L_{0}}
$$

where $\gamma_{S F}$ is the SFE, $b_{p}$ the Burgers vector value of the partial dislocations and $L_{0}$ the length of the sessile partial dislocation of the twin embryo. Steinmetz et al. [34] proposed a model where the twin embryo is a three-layer stacking fault and where $\tau_{t}$ is expressed as :

$$
\tau_{t}=\frac{\gamma_{S F}}{3 b_{p}}+\frac{3 G b_{p}}{L_{0}}
$$

$\tau_{t}$ was estimated with both equations for Fe-22Mn-0.6C TWIP steel, using the following parameters : $\gamma_{S F}=19$ to $31 \mathrm{~mJ} \cdot \mathrm{m}-2, b_{p}=1.47 * 10-10 \mathrm{~m}, G=62.7 \mathrm{GPa}$ and $L_{0}=200 \mathrm{~nm}$ (as measured by Mahato et al. [33] in Fe-27Mn-2.5Si-3.5Al steel deformed by $2 \%$ ) or $261 \mathrm{~nm}$ (proposed by Steinmetz et al. [34] for Fe-22Mn-0.6C steel). Using equation (14) with all the possible combinations of parameters, $\tau_{t}$ ranges from 165 to $246 \mathrm{MPa}$, while using equation(15), it ranges from 149 to $209 \mathrm{MPa}$. The predicted CRSS and the experimental estimates seem thus consistent.

However, some scattering of the apparent CRSS among the monitored grains is observed. This scatter could not be correlated with a scattering in grain size. Based on their detection -by Electron Channeling Contrast Imaging (ECCI)- of the first twins during tensile tests on two batches of Fe-22Mn-0.6C TWIP steel, with 3 or $50 \mu \mathrm{m}$ mean grain size, Guttierez-Urrutia et al. [24] concluded that the influence of the grain size on the twinning stress is well captured by Hall-Petch equation, if the coefficient $K$ in the grain size term, $K / \sqrt{D}$, is $376 \mathrm{MPa} \sqrt{\mu \mathrm{m}}$. They underlined that this is the same value as for the grain-size dependence of the yield stress, and thus of dislocation glide, contrary to the generally accepted idea [4, 24-27], that twinning is more sensitive to the the grain size than dislocation glide. Using this value of $K$, the difference in twinning stress between the smallest and largest grain in table 2 ( 79 and $112 \mu \mathrm{m}$, respectively) should be at most $6 \mathrm{MPa}$, while it is actually between 17 and $52 \mathrm{MPa}$ (due to the incremental nature of the observations, the exact stress at the onset of twinning is not known, but ranges were obtained for each grain, this also leading to a range for the difference between grains. Note that in terms of rigor, this should also be the case for all reported twinning stresses or strain in the literature, that are also based on incremental observations). These data thus do not seem to comply with the Hall-Petch equation for Fe-22Mn-0.6C TWIP steel proposed in [24]. This might partly be due to the fact that the present steel contains $0.2 \% \mathrm{~V}, 0.23 \% \mathrm{Si}$ and $0.19 \% \mathrm{Cr}$, contrary to that investigated in [24], since $\mathrm{V}$ and Si additions were shown to increase the yield stress and reduce the stacking fault energy of TWIP steels $[35,36]$. For the same reason, it is tricky to compare the values of the twinning stress and strain measured in the largest grains of the present microalloyed TWIP steel with those reported, based on ECCI, TEM or EBSD incremental observations for plain Fe-22Mn-0.6C steel by several teams, among which Gutierrez-Urrutia et al. [24] (400 MPa and 4\% for a mean grain size of $3 \mu \mathrm{m}, 270 \mathrm{MPa}$ and 3\% for $50 \mu \mathrm{m}$ ), Barbier et al. [32] (550 MPa and 2\% for a mean grain size of $2.6 \mu \mathrm{m}$ ) or Yang et al. [29] (320 to $345 \mathrm{MPa}$ and 0.56 to $1.58 \%$ for a mean grain size of $25 \mu \mathrm{m}$ ).

Anyway, the scatter in the measured apparent CRSS for twinning among the monitored grains, which does not seem to result from differences in grain size, rather shows the limits of an approach based on Schmid factors, which assumes a uniform stress field. Even though the grain elastic stiffness coefficients in TWIP steels are not well documented, a high elastic anisotropy is generally assumed and could contribute to a substantial heterogeneity of the stress field in the polycrystal. This phenomenon was investigated by Suzuki et al. [37] with finite element simulations at the mesoscale. The authors found that the grains with a high apparent elastic 
modulus along the tensile axis and associated low deformation (e.g. those with a near (111) orientation)-are subjected to an additional tension to ensure compatibility, while the grains with a lower apparent elastic modulus (e.g. those with a near (110) orientation) that deform more readily than average experience an additional compression. This should lower $\tau_{T}$ in the former, and increase it in the latter, in agreement with the lower $\tau_{T}$ measured in grains with a near (111) orientation ( $\approx 166 \mathrm{MPa}$ ) than in grains with a near $(110)$ orientation $(\approx 207 \mathrm{MPa})$.

In addition, the multiple observation of the nucleation of twins at grain boundaries triple points (e.g. grain \#1, figure 4(b)), was also reported by Suzuki et al. [37]. Based on the abovementioned simulations, the authors explained this phenomenon by large stress concentrations, especially when the difference in apparent elastic moduli along the tensile axis between neighboring grains is large.

The ability of the neighbouring grains to accommodate the large stress concentration at the tips of a twin should also be considered to estimate the ease of twin nucleation. Using a crystal elasto-viscoplastic model, Arul Kumar et al. [38-40] studied the stress state in a small agregate of HCP grains induced by the nucleation of a twin across the central grain, for various relative misorientations of its neighbors. They found that twinning induces an intense stress concentration just in the neighbouring grains ahead of the twin tips, and a backstress along the twin in the central grain, which is more pronounced close to the grain boundaries. They noticed that the intensity of this backstress decreases when a slip or twinning system of the neighbouring grains is favourably oriented to accommodate the twin shear. An estimation of the backstress has been proposed based on the relative orientation factor :

$$
m_{\text {rel }}=\left(b_{T} \cdot b_{S}\right)\left(n_{T} \cdot n_{S}\right)
$$

where $b_{T}$ and $n_{T}$ are the Burgers vector and plane normal of the active twinning system in the considered grain, while $b_{s}$ and $n_{s}$ are the Burgers vector and plane normal of the slip or twinning systems likely to be activated in reaction, in the neighbouring grain. Since the backstress opposes the resolved shear stress on the activated twinning system, a favourable orientation of the systems in the neighbouring grains is associated with a high $m_{r e l}$, close to 1 and promotes the development of the twins in the parent grain.

The latter approach was applied to grain \#12, monitored during a tension-compression test under

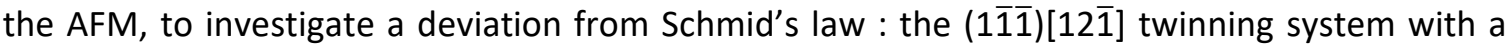

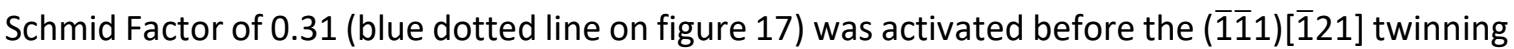
system with a higher Schmid Factor of 0.46 (experimental trace is not visible on figure 17, but schematically represented by the orange dotted line). Figure 17 compares the maximum $m_{\text {rel }}$ computed over all possible twinning and slip systems of each neighbouring grain, when either the former (blue figures) or the latter (orange figures) twinning system of grain \#12 is considered.

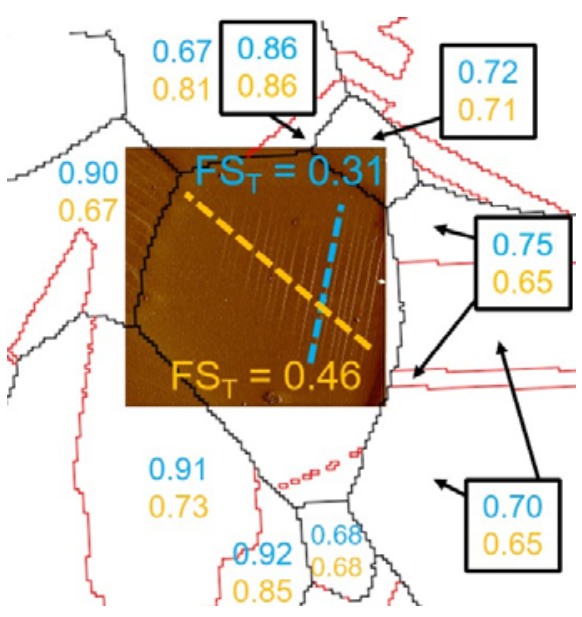


Figure 17: Peak Force Error AFM image of grain \#12 after the first tension up to $443 \mathrm{MPa}$ and neighbouring grains

Out of the 11 neighbouring grains (annealing twins being considered as grains), 8 have a higher maximum $m_{r e l}$ when the activated twinning system is considered, compared to the twinning system with the maximum Schmid factor, and 2 show equal values. The activation of the $(1 \overline{1} \overline{1})[12 \overline{1}]$ system and the lack of activity of the $(\overline{1} \overline{1} 1)[\overline{1} 21]$ system in spite of a higher Schmid factor might therefore be due to an easier accommodation of the twinning shear on the former, thus lowering the backstress which hinders the development of twins.

Overall, the observed scatter of the apparent resolved shear stress for the onset of twinning can be understood especially if one considers the combined effects of a significant elastic anisotropy of the grains, leading to stress concentrations, in particular near triple junctions, and the different ability of surrounding grains to plastically accommodate the twinning shear strain.

\subsection{Threshold and degree of twinning/detwinning/retwinning}

The local monitoring of twinning/detwinning/retwinning achieved in the present study is a significant contribution to the literature on detwinning in FCC alloys. It allows for a renewed discussion of the experimental results and model predictions presented in the literature review.

The experimental observations suggest that after twinning, detwinning processes does not start as soon as loading is reversed, but requires a sufficient variation of the applied stress. Figure 8 (h) shows that detwinning begins for a compression of about $-417 \mathrm{MPa}$, close in absolute value to the stress needed for twinning, which lies between 400 and $475 \mathrm{MPa}$. This observation conflicts with the outcome of molecular dynamics simulations made for nano polycristalline TWIP steel by Mohammadzadeh [7] according to which detwinning begins right at the onset of stress reversal. The present observations are however in agreement with the phase-field energetic approach developed by $\mathrm{Hu}$ et al. [8] in which the resolved shear stress to trigger detwinning was the opposite of that for twinning.

Szczerba et al. [9] also reported the existence of threshold stresses for detwinning in Cu-8.5Al single crystals. They estimated the stresses as $-42 \%$ and $-85 \%$ of the CRSS for twinning for the "reverse" and "pseudo-reverse" detwinning modes, respectively. A comparison with the present estimate of the relative threshold stress for detwinning is nonetheless tricky, since a twinned single crystal, as opposed to a twinned grain in a polycristal, does not undergo the backstress from neighboring grains evidenced numerically by Arul Kumar et al. [38-40]. The latter studies focused on HCP metals, but should also apply to FCC polycristals, in which the backstress induced by neighboring grains might even be stronger, due to the much larger twinning shear strain and elastic stiffness. A backstress opposing the applied shear stress along the twin thus hinders further twinning, as long as the applied stress does not increase. However, it favors the reverse glide of the twinning partial dislocations, if the applied load decreases (especially close to the grain boundaries where it is the strongest), and thus assists detwinning. It should also favor the nucleation of secondary twins on the two coplanar twinning systems, in the vicinity of primary twins as observed in figure 11 , since these systems also undergo a backstress. Given the $\pm 120^{\circ}$ misorientation of their Burgers vector around the plane normal with respect to that of the primary twinning system, the value of the backstress on the secondary systems should however be twice lower than on the primary system, causing secondary twinning to be promoted as well, but to a lesser extent than detwinning.

After prestraining in tension a Fe-24Mn-3Al-2Si-1Ni-0.06C TWIP steel by $12.8 \%$-this corresponding approximately to a tensile stress of $600 \mathrm{MPa}-$, McCormack et al. [14] reported complete detwinning--or at least sufficient to make twin bundles undetectable by EBSD mappings with a stepsize of $100 \mathrm{~nm}$ - for a compression stress of $-600 \mathrm{MPa}$, corresponding to a residual strain of $3.1 \%$. The present HR-DIC measurements (Figures $6(b)$ and (c)) suggest only partial detwinning in grain $\# 2$, after a tensile plastic strain of $4.9 \%$ at $475 \mathrm{MPa}$, during subsequent 
compression at $-475 \mathrm{MPa}\left(\varepsilon_{p} \approx 2.3 \%\right.$ ). In the same way, the AFM observations of grain \#4 (Figures $8(\mathrm{~d}),(\mathrm{g})$ and $(\mathrm{h})$ ) indicate the complete disappearance of only two out of the five twin bundles ( $\mathrm{t}_{1}$ and $\mathrm{t}_{3}$ ) that appeared in tension between 400 and $574 \mathrm{MPa}\left(\varepsilon_{p}<5 \%\right)$, for a compression stress of $-522 \mathrm{MPa}$, while the height of the three others $\left(t_{2}, t_{4}\right.$ and $\left.t_{5}\right)$ was only partially reduced. Furthermore, at $\varepsilon_{p}=0.5 \%$, detwinning was even more partial (Figures 14(c) and (d)) upon successive load reversals. The combination of these observations suggests that a higher prestrain makes detwinning more complete. This would be consistent with the rise of the neigboring grainsinduced backstress with the twinned fraction in a grain, that McCormack et al. [14] introduced in a crystal plasticity model, and that D'Hondt retrieved by very simple 2D FE computations [18]. On the other hand, a very large prestrain likely to activate secondary twinning and multiple glide systems might, at the contrary, hinder detwinning, due to interactions between the partial dislocations of the primary twin and many intersecting dislocations. This question, that matters for the understanding and prediction of springback effects during forming processes [31], deserves further attention.

It should be emphasized that when several parallel twins with the same Burgers vector were present in a grain, their detwinning kinetics and degree upon stress reversal varied significantly (Figures $7(\mathrm{~d})$ and $8(\mathrm{~h})$ ). The phenomenon, assisted by the backstress from surrounding grains, therefore seems to be controlled by very local conditions, that only full-field crystal plasticity finite element or phase-field simulations seem likely to capture.

Load reversals were observed to trigger detwinning and/or secondary coplanar twinning inducing axial plastic flow in the opposite direction, but not the nucleation of new twins on noncoplanar systems. This might partly be due to 1 ) the limited applied stress and strain amplitudes, unfavorable to twinning on systems with a smaller Schmid factor 2) the obstacles that primary twins constitute for intersecting twins and 3 ) the strong polarization of the stress field associated with the back stress along the primary twinning plane.

\subsection{Evolution of the twinning activity during cyclic plasticity}

The statistical analysis of the twinning activity over an area containing nearly 100 grains during the tension- compression test at $\Delta \varepsilon_{p} / 2=0.5 \%$ run under the AFM showed an increase of the mean number of activated twinning planes per grain (from 0.85 to 1.15) as the stress range rose from 426 to $592 \mathrm{MPa}$ (Figure 16(a)). This is consistent with our TEM observations at the end of the hardening stage of the macroscale counterpart of this test [18] which revealed a substantial proportion of twinned grains, each showing 10 to $45 \%$ twinned fraction, in the form of 160 to 250 $\mathrm{nm}$-thick twin bundles, but nearly always along a single plane. Twinning along two different planes was much more frequent by the end of the cyclic hardening stage at $\Delta \varepsilon_{p} / 2=0.8 \%$, for which the stress range reached $732 \mathrm{MPa}$ [18].

The statistics per class of grain size (Figure 16(b)) reveal that while the number of activated twinning systems remained low and nearly constant ( 0.3 to 0.4 ) in the smallest grains (less than $20 \mu \mathrm{m}$ large), it increased progressively from 1.6 to 2.1 in the largest grains (60 to $100 \mu \mathrm{m}$ ). As mentioned in 3.3, values above 1 do not necessary imply twinning on multiple planes, but mostly refer in the present case to the activation, in the largest grains, of different coplanar twinning systems that accommodate plastic strain in tension and compression, respectively. Figure 16(b) suggests that while the smallest grains twin less frequently, but as early as the largest ones, they do not readily activate more than a single system. The latter observation is consistent with many others in the literature [24, 31]. In the framework of cyclic plasticity, it suggests that reversed plastic flow in these grains is accommodated either merely by reversed dislocation glide, or by reversed dislocation glide and twinning/detwinning on a single system.

The present AFM and SEM observations within selected grains suggest that an increase of the stress amplitude is required for the twin fraction to grow. This is in agreement with the argument on the effects of the backstress presented above, since a stress increment is necessary to 
overcome it and allow the nucleation of new twins. It is also in agreement with the TEM observations of Niendorf et al. [41], who did not notice any twin evolution after cyclic tests under constant strain amplitude on a pre-strained Fe-22Mn-0.5C TWIP steel that showed almost no cyclic hardening. However, the fact that Niendorf et al. reported a thickening of the twins, during cyclic tests run on the same, non pre-strained, TWIP steel showing, in that case, cyclic softening is difficult to reconcile with the present AFM observations. No such twin evolution was indeed noted during the softening stage (beyond the $100^{\text {th }}$ cycle) of the test at $\Delta \sigma / 2=511 \mathrm{MPa}$ (Figure 12). On the contrary, the observations of Lambers et al. [42], who after a 30 or $60 \%$ monotonic pre-strain did not notice any significant evolution of the twins during subsequent strain-controlled tension-compression tests on Fe-24Mn-6.5Ni-8.5Cr TWIP steel showing cyclic softening, are more in line with the present observations.

During the cyclic hardening stage of the plastic strain-controlled test, the twin fraction in the monitored grains was found to rise according to a ratchetting evolution, with intra-cycle oscillations of decreasing amplitude. A tendency towards the saturation of the twin fraction was observed, in accordance with the deceleration of cyclic hardening before the beginning of the softening stage. The crystal plasticity simulations done by Saleh et al. [43] over 6 tensioncompression cycles at $\Delta \varepsilon / 2=1 \%$ on a TWIP steel showing cyclic strain-hardening also predict a gradual increase of the global twin fraction. Note however that in these simulations, the twin fraction could not decrease since detwinning was not considered.

A tentative schematic description of the twinning activity in suitably oriented grains during the cyclic hardening stage of a strain or plastic-strain-controlled reversed loading is presented in 6 steps on figure 18(a) :

- Twinning does not occur until cyclic hardening has allowed the minimum or maximum stress of the cycle to reach the twinning stress (dislocation glide is still sufficient to accommodate reverse plastic strain),

- When this condition is met locally, one or several twin bundles can form, and as a consequence, the neighboring grains induce a back stress, which is higher when they do not have a slip or twinning system with a high $m_{r e l}$ (Equation (16)), and which hinders further twinning on the primary system, unless the applied stress rises further,

- Upon unloading and then load reversal, the twin bundles first do not evolve, in spite of the back stress, until the sum of this back stress and of the reversed applied load reaches a critical value,

- When this condition is met, partial or complete detwinning and/or coplanar secondary twinning inducing a reverse axial strain may occur, and, as a consequence, the back stress is reduced, or even cancelled,

- Upon subsequent forward reloading the twin bundles first do not evolve, until the sum of the potentially remaining back stress and of the forward applied load reaches a critical value

- Partial retwinning then starts and, if the peak stress has increased, compared to the previous peak, nucleation of new twins or growth of existing ones can occur.

As a result (Figure 18(b)), the twin fraction increases in a ratchetting way, with smaller and smaller oscillations during each cycle, as long as the stress amplitude rises. The relatively fast damping of these oscillations implies that the fraction of the plastic strain range accommodated by twinning decreases. When the stress range reaches a steady-state, or starts decreasing due to cyclic softening [18] the twin fraction saturates, and cyclic plasticity is then accommodated merely by dislocation glide. 
(a)

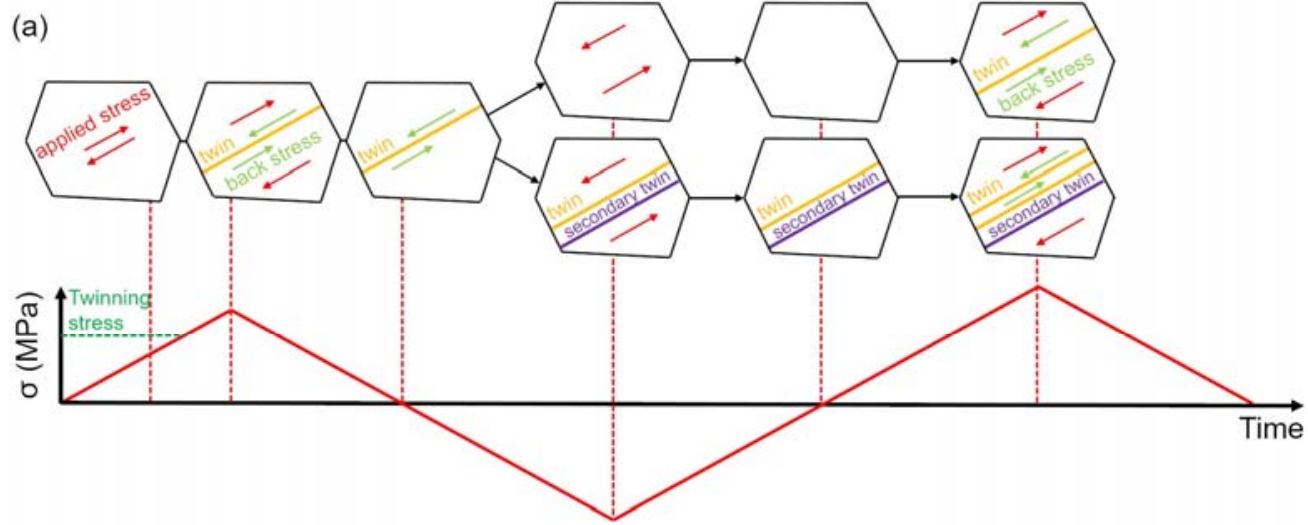

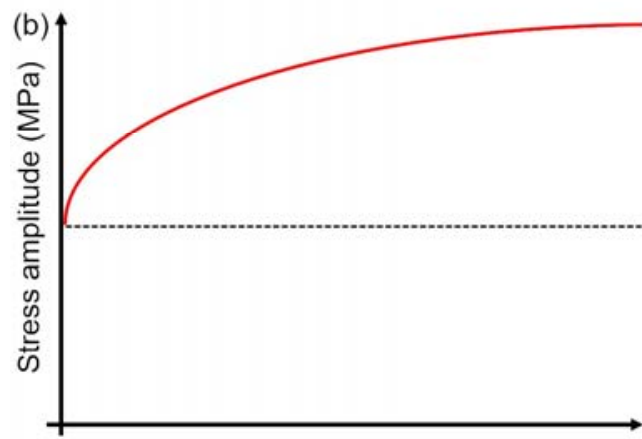

Number of load reversals

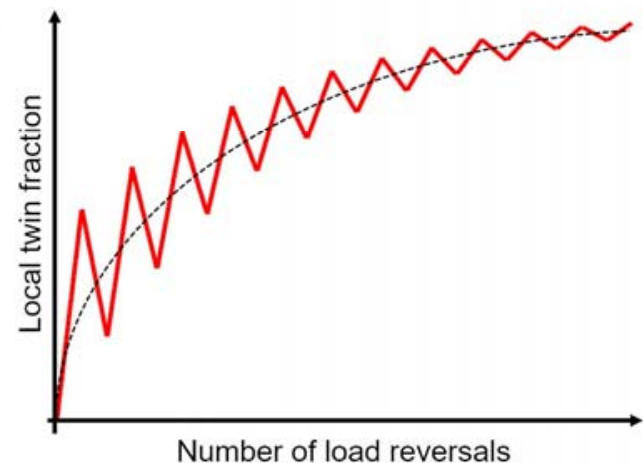

Figure 18: Schematic description of the twinning activity during the cyclic hardening stage of a strain or plastic-straincontrolled reversed loading: (a) deformation steps in suitably oriented grain and (b) evolution of the twin fraction associated with the rise of the stress amplitude

The cyclic variations in intensity of the neutron diffraction peaks observed by Xie et al. $[12,13]$ in a TWIP steel during a tension-compression test at $\Delta \varepsilon / 2=0.8 \%$ is qualitatively compatible with the twinning/detwinning/retwinning process observed in the present work in favorably oriented grains. However, the larger peak intensity variation amplitude reported at the $1000^{\text {th }}$ cycle if compared to the $1^{\text {st }}$ one was attributed by the authors to an intensification of twinning/detwinning/retwinning, while (surprisingly) almost no cyclic hardening was observed between those cycles. It is at variance with the present-observations. The latter rather suggest that the increase in twinning activity is a consequence of cyclic hardening, and that even when the twin fraction rises with the stress amplitude, from cycle to cycle, twinning/detwinning/retwinning accommodates a decreasing fraction of the plastic strain range.

While many successful TEM observations of twinned grains were made in parallel with this study on "traditionally prepared" thin foils (mechanical thinning followed by electropolishing) [18], an attempt to perform TEM observations on grains previously monitored with the AFM (using FIB extraction of the foil) failed, presumably because such rectangular foils are smaller (10 $\mu \mathrm{m}$ deep and $20 \mu \mathrm{m}$ wide), and thus, due to the removal of the constraint by neighboring grains, the local stress state was substantially modified and the twins became unstable and disappeared. To avoid such perturbations, $\mathrm{ECCl}$ observations of grains in their environment during reversed cyclic tests might constitute a valuable additional way to document detwinning/retwinning with an appropriate resolution.

\section{Conclusions}

In situ tensile and tension-compression tests under constant stress range or plastic strain range were carried out on a Fe-22Mn-0.6C TWIP steel inside a SEM or under an AFM. Quantitative data on mechanical twinning within selected grains particularly prone to twinning, and statistics on an area containing nearly hundred grains, were obtained either from the analysis of the plastic strain field measured with sub-micron resolution by HR-DIC, or from AFM topographic measurements of step heights at emerging twins. The main conclusions are : 
- Although its order of magnitude (148 to $215 \mathrm{MPa}$ ) is consistent with the predictions of two twinning models, the apparent CRSS for twinning estimated based on Schmid factors is intrinsically scattered, because of the heterogeneity of the stress field. The twinning propensity of a grain also seems to depend on the ability of its neighbors to accommodate the twinning shear and thus not inducing too much backstress.

- A method previously developed to estimate the mean twin fraction in a grain, knowing its orientation from EBSD and its mean axial and transverse plastic strains from DIC, was implemented at a much more local scale, allowing the computation of twin fraction maps in a grain with a resolution of 150 to $250 \mathrm{~nm} /$ pixel.

- In tension-compression, the local twin fraction evolved according to a hysteresis loop versus the applied stress. Detwinning, as well as retwinning, which were often only partial, in spite of a fully reversed loading, did not seem to start at the onset of stress reversal, but both required a sufficient variation of the stress, close to the twin nucleation stress in absolute value.

- A given grain could accommodate reversed plastic strain in tension-compression through twinning/detwinning, but also through twinning on different coplanar systems inducing an axial plastic strain of opposite sign.

- Under fixed stress amplitude, after substantial twinning in large and favorably oriented grains during the first ramp, associated with a significant monotonic plastic strain-and partial or even complete detwinning during the first compression half-cycle, the amplitude of plastic deformation accommodated by twinning/detwinning within each cycle decreased, and the twin fraction reached a steady-state.

- Under fixed plastic strain range, the twin fraction in favorably oriented grains, and the mean number of active twinning systems per grain both increased during cyclic hardening, especially in the largest grains. However, in spite of the ratchetting increase of the twin fraction, twinning/detwinning accommodated a smaller and smaller part of the plastic strain range.

\section{A. Twinning and slip Schmid factors of the monitored grains and trace analysis}

Once the Euler angles of a grain are known from EBSD, the rotation matrix, $G$, from the crystallographic axes to the macroscopic axes is also known. In the macroscopic axes, the plane normal $\vec{n}$ and shearing direction $\vec{m}$ of a slip or twinning system characterized respectively by $\vec{N}$ and $\vec{M}$ in the crystal axes are :

$$
\begin{aligned}
& \vec{n}=G \vec{N} \\
& \vec{m}=G \vec{M}
\end{aligned}
$$

The resolved shear stress on a slip or twinning system for an applied a stress state tensor $\sigma$ is

$$
\tau=\sigma_{i j} R_{i j}
$$

where $R_{i j}$ is the orientation tensor of the grain.

In the particular case of a uniaxial tension or compression applied along the macroscopic axis 1 , only $\sigma_{11}$ is non zero, equation (19) reduces to :

$$
\tau=\sigma_{11} R_{11}
$$

In other words, the Schmid factor is equal to $R_{11}$. Table 3 below gathers the values for all the possible slip and twinning systems of the grains mentioned above. 
Besides, the trace of a given slip or twinning plane of normal $\vec{N}$ on the specimen surface of normal $\vec{Z}$ is $\vec{T}=\vec{N} \wedge \vec{Z}$, and the angle between the tensile axis $\vec{X}$ and the trace is : $\cos ^{-1}(\vec{T}, \vec{X})$. By comparing the measured angle between slip or twin traces relative to the tensile axis and the computed angles for the four possible slip or twinning planes, the identification of the plane is possible. Furthermore, for AFM images of twins, the comparison of their emergence angle with the three values predicted by equation (8) on a given plane allows the Burgers vector to be determined. 
Table 3

Twinning and slip Schmid factors of the grains mentioned in the Experimental observations section

\begin{tabular}{|c|c|c|c|c|c|c|c|c|c|c|c|c|}
\hline Grain \# & \multicolumn{3}{|c|}{ (111) } & \multicolumn{3}{|c|}{$(\overline{1} 1 \overline{1})$} & \multicolumn{3}{|c|}{$(\overline{1} \overline{1} 1)$} & \multicolumn{3}{|c|}{$(1 \overline{1} \overline{1})$} \\
\hline Twinning & $11 \overline{2}]$ & $\overline{2} 11]$ & $1 \overline{2} 1]$ & $\overline{1} 12]$ & $21 \overline{1}]$ & $\overline{1} \overline{2} \overline{1}]$ & $\overline{1} \overline{1} \overline{2}]$ & $2 \overline{1} 1]$ & $\overline{1} 21]$ & $1 \overline{1} 2]$ & $\overline{2} \overline{1} \overline{1}]$ & $12 \overline{1}]$ \\
\hline 1 & 0.27 & -0.12 & -0.15 & -0.19 & 0.38 & -0.18 & -0.06 & 0.08 & -0.03 & -0.17 & -0.12 & 0.29 \\
\hline 2 & 0.09 & 0.00 & -0.09 & -0.19 & 0.49 & -0.30 & -0.16 & 0.44 & -0.28 & 0.02 & 0.00 & -0.02 \\
\hline 3 & 0.25 & 0.18 & -0.44 & 0.20 & 0.29 & -0.49 & 0.20 & 0.29 & -0.49 & 0.25 & 0.19 & -0.44 \\
\hline 4 & 0.01 & -0.03 & 0.02 & 0.48 & -0.35 & -0.13 & -0.02 & -0.23 & 0.26 & 0.33 & -0.32 & -0.01 \\
\hline 5 & 0.03 & 0.06 & -0.10 & 0.31 & 0.06 & -0.37 & -0.01 & 0.30 & -0.29 & 0.46 & -0.08 & -0.38 \\
\hline 6 & 0.45 & -0.37 & -0.08 & 0.03 & -0.07 & 0.04 & 0.30 & -0.36 & 0.06 & -0.02 & -0.29 & 0.31 \\
\hline 7 & 0.25 & -0.46 & 0.22 & 0.24 & -0.46 & 0.22 & 0.23 & -0.48 & 0.25 & 0.22 & -0.48 & 0.25 \\
\hline 8 & -0.06 & -0.13 & 0.19 & 0.24 & -0.11 & -0.13 & -0.06 & 0.20 & -0.14 & 0.46 & -0.23 & -0.24 \\
\hline 9 & 0.23 & 0.16 & -0.39 & 0.19 & 0.30 & -0.50 & 0.15 & 0.33 & -0.48 & 0.28 & 0.14 & -0.42 \\
\hline 10 & 0.32 & 0.11 & -0.43 & 0.11 & 0.34 & -0.46 & 0.22 & 0.27 & -0.50 & 0.19 & 0.16 & -0.35 \\
\hline 11 & -0.01 & -0.08 & 0.09 & 0.43 & -0.25 & -0.18 & 0.00 & 0.02 & -0.02 & 0.49 & -0.28 & -0.22 \\
\hline 12 & 0.04 & -0.07 & 0.02 & 0.29 & -0.27 & -0.02 & -0.09 & -0.37 & 0.46 & 0.05 & -0.35 & 0.31 \\
\hline 13 & 0.40 & -0.17 & -0.23 & -0.11 & 0.30 & -0.19 & 0.13 & 0.00 & -0.13 & -0.09 & -0.12 & 0.20 \\
\hline Slip & [110] & [101] & [011] & [110] & [101] & [011] & [110] & [101] & [011] & [110] & [101] & [011] \\
\hline 1 & -0.02 & 0.22 & 0.24 & 0.32 & -0.33 & -0.01 & 0.06 & 0.08 & 0.02 & 0.24 & -0.03 & -0.26 \\
\hline 2 & -0.05 & 0.05 & 0.11 & 0.45 & -0.39 & 0.06 & 0.41 & 0.35 & -0.07 & -0.01 & 0.01 & 0.02 \\
\hline 3 & -0.36 & 0.04 & 0.40 & 0.45 & -0.05 & 0.40 & 0.45 & 0.05 & -0.40 & -0.36 & 0.04 & 0.40 \\
\hline 4 & 0.03 & 0.02 & -0.01 & -0.13 & 0.48 & 0.35 & -0.28 & -0.12 & 0.16 & 0.18 & 0.38 & 0.19 \\
\hline 5 & -0.09 & -0.02 & 0.07 & 0.25 & 0.15 & 0.40 & 0.34 & 0.18 & -0.16 & -0.18 & 0.31 & 0.48 \\
\hline 6 & 0.16 & 0.48 & 0.31 & -0.07 & 0.06 & -0.01 & -0.24 & -0.38 & -0.13 & 0.34 & 0.15 & -0.19 \\
\hline 7 & 0.39 & 0.41 & 0.02 & -0.39 & 0.40 & 0.01 & -0.42 & -0.41 & 0.01 & 0.42 & 0.40 & -0.02 \\
\hline 8 & 0.18 & 0.04 & -0.14 & 0.01 & 0.20 & 0.22 & 0.20 & 0.15 & -0.05 & -0.01 & 0.40 & 0.40 \\
\hline 9 & -0.32 & 0.04 & 0.35 & 0.46 & -0.06 & 0.40 & 0.47 & 0.11 & -0.36 & -0.32 & 0.08 & 0.41 \\
\hline 10 & -0.32 & 0.12 & 0.44 & 0.46 & -0.13 & 0.33 & 0.44 & 0.03 & -0.42 & -0.30 & 0.01 & 0.31 \\
\hline 11 & 0.10 & 0.04 & -0.05 & -0.04 & 0.39 & 0.35 & 0.02 & 0.01 & -0.01 & 0.03 & 0.45 & 0.41 \\
\hline 12 & 0.05 & 0.06 & 0.01 & -0.15 & 0.33 & 0.18 & -0.48 & -0.16 & 0.32 & 0.38 & 0.23 & -0.15 \\
\hline 13 & -0.03 & 0.33 & 0.37 & 0.29 & -0.24 & 0.05 & 0.07 & -0.08 & -0.15 & 0.19 & 0.02 & -0.17 \\
\hline
\end{tabular}

\section{Acknowledgments}

The authors are grateful for the support of ArcelorMittal who provided the material and samples studied in thiswork, and more specifically to Bastien Weber and Nicolas Charbonnier for their continued interest in this work.

\section{Data availability}

The raw/processed data required to reproduce these findings cannot be shared at this time due to technical or time limitations.

\section{References}

[1] J. Wang, N. Li, O. Anderoglu, X. Zhang, A. Misra, J. Huang, J. Hirth, Detwinning mechanisms for growth twins in face-centered cubic metals, Acta Materialia 58 (2010) 2262-2270. https://doi.org/10.1016/j.actamat.2009.12.013

[2] C. Shute, B. Myers, S. Xie, S.-Y. Li, T. Barbee, A. Hodge, J. Weertman, Detwinning, damage and crack initiation during cyclic loading of cu samples containing aligned nanotwins, Acta Materialia 59 (2011) 4569-4577. https://doi.org/10.1016/j.actamat.2011.04.002

[3] S. Ni, Y. B. Wang, X. Z. Liao, H. Q. Li, R. B. Figueiredo, S. P. Ringer, T. G. Langdon, Y. T. Zhu, Effect of grain size on the competition between twinning and detwinning in nanocrystalline metals, Physical Review B 84 (2011). https://doi.org/10.1103/physrevb.84.235401

[4] Y. T. Zhu, X. Z. Liao, X. L. Wu, J. Narayan, Grain size effect on deformation twinning and detwinning, Journal of Materials Science 48 (2013) 4467-4475. https://doi.org/10.1007/s10853-013-7140-0

[5] X. An, S. Ni, M. Song, X. Liao, Deformation twinning and detwinning in face-centered cubic metallic materials, Advanced Engineering Materials 22 (2019) 1900479. https://doi.org/10.1002/adem.201900479 
[6] Y. Zhu, X. Wu, X. Liao, J. Narayan, L. Kecskés, S. Mathaudhu, Dislocation-twin interactions in nanocrystalline fcc metals, Acta Materialia 59 (2011) 812-821. https://doi.org/10.1016/j.actamat.2010.10.028

[7] R. Mohammadzadeh, Reversible deformation in nanocrystalline TWIP steel during cyclic loading by partial slip reversal and detwinning, Materials Science and Engineering: A 782 (2020) 139251. https://doi.org/10.1016/j.msea.2020.139251

[8] S. Hu, C. H. Henager, L. Chen, Simulations of stress-induced twinning and de-twinning: A phase field model, Acta Materialia 58 (2010) 6554-6564. https://doi.org/10.1016/j.actamat.2010.08.020

[9] M. Szczerba, S. Kopacz, M. Szczerba, Experimental studies on detwinning of face-centered cubic deformation twins, Acta Materialia 104 (2016) 52-61. https://doi.org/10.1016/j.actamat.2015.11.025

[10] B. Q. Li, M. L. Sui, B. Li, E. Ma, S. X. Mao, Reversible twinning in pure aluminum, Physical Review Letters 102 (2009). https://doi.org/10.1103/physrevlett.102.205504

[11] A. A. Saleh, B. Clausen, D. W. Brown, E. V. Pereloma, C. H. Davies, C. N. Tomé, A. A. Gazder, On the feasibility of partial slip reversal and de-twinning during the cyclic loading of TWIP steel, Materials Letters 182 (2016) 294-297. https://doi.org/10.1016/j.matlet.2016.07.005

[12] Q. Xie, J. Liang, A. Stoica, R. Li, P. Yang, Z. Zhao, J. Wang, H. Lan, R. Li, K. An, In-situ neutron diffraction study on the tension-compression fatigue behavior of a twinning induced plasticity steel, Scripta Materialia 137 (2017) 83-87. https://doi.org/10.1016\%2Fj.scriptamat.2017.04.041

[13] Q. Xie, Y. Chen, P. Yang, Z. Zhao, Y. Wang, K. An, In-situ neutron diffraction investigation on twinning/detwinning activities during tension-compression load reversal in a twinning induced plasticity steel, Scripta Materialia 150 (2018) 168-172. https://doi.org/10.1016\%2Fj.scriptamat.2018.03.017

[14] S. J. McCormack, W. Wen, E. V. Pereloma, C. N. Tomé, A. A. Gazder, A. A. Saleh, On the first direct observation of de-twinning in a twinning-induced plasticity steel, Acta Materialia 156 (2018) 172-182. https://doi.org/10.1016/j.actamat.2018.06.029

[15] M. Koyama, T. Sawaguchi, K. Tsuzaki, Deformation twinning behavior of twinning-induced plasticity steels with different carbon concentrations - part 1: Atomic force microscopy and electron backscatter diffraction measurements, ISIJ International 55 (2015) 1747-1753. https://doi.org/10.2355/isijinternational.isijint-2015-069

[16] C. Coupeau, F. Tranchant, J. Vergnol, J. Grilhé, Atomic force microscopy of twin formation in low-stacking fault CuAl alloy, The European Physical Journal Applied Physics 6 (1999) 1-6. https://doi.org/10.1051/epjap:1999145

[17] Y. Yang, L. Wang, T. R. Bieler, P. Eisenlohr, M. A. Crimp, Quantitative atomic force microscopy characterization and crystal plasticity finite element modeling of heterogeneous deformation in commercial purity titanium, Metallurgical and Materials Transactions A 42 (2010) 636-644. https://doi.org/10.1007/s11661-010-0475-0

[18] C. D'Hondt, Analyse de la plasticité cyclique d'un acier TWIP et du rôle du maclage/démaclage à l'aide d'imagerie et de mesures de champs sub-micrométriques, Ph.D. thesis, Ecole Polytechnique, 2020.

[19] S. Allain, J.-P. Chateau, O. Bouaziz, S. Migot, N. Guelton, Correlations between the calculated stacking fault energy and the plasticity mechanisms in fe-mn-c alloys, Materials Science and Engineering: A 387-389 (2004) 158-162. https://doi.org/10.1016/j.msea.2004.01.059

[20] A. Saeed-Akbari, L. Mosecker, A. Schwedt, W. Bleck, Characterization and prediction of flow behavior in highmanganese twinning induced plasticity steels: Part i. mechanism maps and work-hardening behavior, Metallurgical and Materials Transactions A 43 (2011) 1688-1704. https://doi.org/10.1007/s11661-011-0993-4

[21] A. Dumay, J.-P. Chateau, S. Allain, S. Migot, O. Bouaziz, Influence of addition elements on the stacking-fault energy and mechanical properties of an austenitic fe-mn-c steel, Materials Science and Engineering: A $483-484$ (2008) 184-187. https://doi.org/10.1016/j.msea.2006.12.170

[22] J. Nakano, P. J. Jacques, Effects of the thermodynamic parameters of the hcp phase on the stacking fault energy calculations in the fe-mn and fe-mn-c systems, Calphad 34 (2010) 167-175. https://doi.org/10.1016/j.calphad.2010.02.001

[23] L. Allais, M. Bornert, T. Bretheau, D. Caldemaison, Experimental characterization of the local strain field in a heterogeneous elastoplastic material, Acta Metallurgica et Materialia 42 (1994) 3865-3880. https://doi.org/10.1016/0956-7151(94)90452-9

[24] I. Gutierrez-Urrutia, S. Zaefferer, D. Raabe, The effect of grain size and grain orientation on deformation twinning in a fe-22wt.\% mn-0.6wt.\% c TWIP steel, Materials Science and Engineering: A 527 (2010) 3552-3560. https://doi.org/10.1016/j.msea.2010.02.041

[25] E. El-Danaf, S. R. Kalidindi, R. D. Doherty, Influence of grain size and stacking-fault energy on deformation twinning in fcc metals, Metallurgical and Materials Transactions A 30 (1999) 1223-1233. https://doi.org/10.1007/s11661999-0272-9

[26] K. Rahman, V. Vorontsov, D. Dye, The effect of grain size on the twin initiation stress in a TWIP steel, Acta Materialia 89 (2015) 247-257. https://doi.org/10.1016/j.actamat.2015.02.008

[27] M. Meyers, O. Vöhringer, V. Lubarda, The onset of twinning in metals: a constitutive description, Acta Materialia 49 (2001) 4025-4039. https://doi.org/10.1016/s1359-6454(01)00300-7

[28] C. Efstathiou, H. Sehitoglu, Strain hardening and heterogeneous deformation during twinning in hadfield steel, Acta Materialia 58 (2010) 1479-1488. https://doi.org/10.1016/j.actamat.2009.10.054

[29] H. Yang, V. Doquet, Z. Zhang, Micro-scale measurements of plastic strain field, and local contributions of slip and twinning in TWIP steels during in situ tensile tests, Materials Science and Engineering: A 672 (2016) 7-14. https://doi.org/10.1016/j.msea.2016.06.064

[30] S. R. Kalidindi, Modeling the strain hardening response of low SFE FCC alloys, International Journal of Plasticity 14 (1998) 1265-1277. https://doi.org/10.1016/s0749-6419(98)00054-0 
[31] J. Benito, R. Cobo, W. Lei, J. Calvo, J. Cabrera, Stress-strain response and microstructural evolution of a FeMnCAI TWIP steel during tension-compression tests, Materials Science and Engineering: A 655 (2016) 310-320. https://doi.org/10.1016/j.msea.2016.01.004

[32] D. Barbier, N. Gey, S. Allain, N. Bozzolo, M. Humbert, Analysis of the tensile behavior of a TWIP steel based on the texture and microstructure evolutions, Materials Science and Engineering: A 500 (2009) 196-206. https://doi.org/10.1016/j.msea.2008.09.031

[33] B. Mahato, S. Shee, T. Sahu, S. G. Chowdhury, P. Sahu, D. Porter, L. Karjalainen, An effective stacking fault energy viewpoint on the formation of extended defects and their contribution to strain hardening in a fe-mn-si-al twinning-induced plasticity steel, Acta Materialia 86 (2015) 69-79. https://doi.org/10.1016/j.actamat.2014.12.015

[34] D. R. Steinmetz, T. Jäpel, B. Wietbrock, P. Eisenlohr, I. Gutierrez-Urrutia, A. Saeed-Akbari, T. Hickel, F. Roters, D. Raabe, Revealing the strain-hardening behavior of twinning-induced plasticity steels: Theory, simulations, experiments, Acta Materialia 61 (2013) 494-510. https://doi.org/10.1016/j.actamat.2012.09.064

[35] H.-W. Yen, M. Huang, C. Scott, J.-R. Yang, Interactions between deformation-induced defects and carbides in a $\begin{array}{lllllll}\text { vanadium-containing TWIP steel, Scripta Materialia } 66 & \text { (2012) } 1018-1023 .\end{array}$ https://doi.org/10.1016/j.scriptamat.2012.02.002

[36] K. Jeong, J.-E. Jin, Y.-S. Jung, S. Kang, Y.-K. Lee, The effects of si on the mechanical twinning and strain hardening of fe-18mn-0.6c twinning-induced plasticity steel, Acta Materialia 61 (2013) 3399-3410. https://doi.org/10.1016/j.actamat.2013.02.031

[37] S. Suzuki, K. Hotta, E. P. Kwon, S. Fujieda, K. Shinoda, M. Kumagai, K. Kajiwara, M. Sato, S. Sato, Characterization of evolution of microscopic stress and strain in high-manganese twinning-induced plasticity steel, ISIJ International 55 (2015) 2158-2165. https://doi.org/10.2355/isijinternational.isijint-2014-378

[38] M. Arul Kumar, A. Kanjarla, S. Niezgoda, R. Lebensohn, C. Tomé, Numerical study of the stress state of a deformation twin in magnesium, Acta Materialia 84 (2015) 349-358. https://doi.org/10.1016/j.actamat.2014.10.048

[39] M. Arul Kumar, I. Beyerlein, C. Tomé, Effect of local stress fields on twin characteristics in HCP metals, Acta Materialia 116 (2016) 143-154. https://doi.org/10.1016/j.actamat.2016.06.042

[40] M. Arul Kumar, I. J. Beyerlein, R. A. Lebensohn, C. N. Tomé, Modeling the effect of neighboring grains on twin growth in HCP polycrystals, Modelling and Simulation in Materials Science and Engineering 25 (2017) 064007. https://doi.org/10.1088/1361-651x/aa7bbb

[41] T. Niendorf, C. Lotze, D. Canadinc, A. Frehn, H. Maier, The role of monotonic pre-deformation on the fatigue performance of a highmanganese austenitic TWIP steel, Materials Science and Engineering: A 499 (2009) 518-524. https://doi.org/10.1016/j.msea.2008.09.033

[42] H.-G. Lambers, C. Rüsing, T. Niendorf, D. Geissler, J. Freudenberger, H. Maier, On the low-cycle fatigue response of pre-strained austenitic fe61mn24ni6.5cr8.5 alloy showing TWIP effect, International Journal of Fatigue 40 (2012) 51-60. https://doi.org/10.1016/j.ijfatigue.2012.01.002

[43] A. A. Saleh, E. V. Pereloma, B. Clausen, D. W. Brown, C. N. Tomé, A. A. Gazder, On the evolution and modelling of lattice strains during the cyclic loading of TWIP steel, Acta Materialia 61 (2013) 5247-5262. https://doi.org/10.1016/j.actamat.2013.05.017 